\title{
Commercial Free-Range Laying Hens' Preferences for Shelters with Different Sunlight Filtering Percentages
}

\author{
Md Sohel Rana ${ }^{1,2,3}{ }^{(0)}$, Caroline Lee ${ }^{2}\left(\mathbb{D}, \mathrm{Jim}_{\text {M. }}\right.$ Lea $^{2}$ and Dana L. M. Campbell ${ }^{2, *}$ \\ 1 Department of Animal Science, School of Environmental and Rural Science, University of New England, \\ Armidale, NSW 2351, Australia; ranasoheldvm06@gmail.com \\ 2 Agriculture and Food, Commonwealth Scientific and Industrial Research Organisation (CSIRO), \\ Armidale, NSW 2350, Australia; caroline.lee@csiro.au (C.L.); jim.lea@csiro.au (J.M.L.) \\ 3 Department of Livestock Services, Ministry of Fisheries and Livestock, Dhaka 1215, Bangladesh \\ * Correspondence: dana.campbell@csiro.au
}

check for updates

Citation: Rana, M.S.; Lee, C.; Lea, J.M.; Campbell, D.L.M. Commercial Free-Range Laying Hens' Preferences for Shelters with Different Sunlight Filtering Percentages. Animals 2022, 12, 344. https://doi.org/10.3390/ ani12030344

Academic Editors:

Victoria Sandilands and

Tina Widowski

Received: 4 December 2021

Accepted: 24 January 2022

Published: 31 January 2022

Publisher's Note: MDPI stays neutral with regard to jurisdictional claims in published maps and institutional affiliations.

Copyright: (C) 2022 by the authors. Licensee MDPI, Basel, Switzerland. This article is an open access article distributed under the terms and conditions of the Creative Commons Attribution (CC BY) license (https:// creativecommons.org/licenses/by/ $4.0 /)$.
Simple Summary: Australian sunlight is intense, and may impact range use by free-range hens. Range design and management are important for optimising commercial layer farms where artificial shelters may offer protection for ranging hens. This study investigated preferences among 34-40-week-old hens for artificial shade cloth shelters of different densities, using two flocks on a commercial farm during the summer. Three types of sunlight-filtering shade cloth shelters, i.e., blocking $50 \%, 70 \%$, and $90 \%$ of ultraviolet (UV) light, each with three replicates, were placed on the range for each flock. The number of hens under each shelter was counted at 30-min intervals using image snapshots from video recordings for 14 to 17 days. An on-site weather station recorded sunlight intensity across different spectra, ambient temperature, and relative humidity. During the day, hens generally preferred the $90 \%$, followed by $70 \%$ and $50 \%$ sunlight-filtering shelters. However, fewer hens were observed underneath shelters during times of peak sun intensity. Shelter preferences were mostly impacted by ambient temperature in both flocks, with all sunlight spectra having different degrees of effect depending on the shelter type and flock. Overall, shelters comprising higher densities of sunlight-filtering artificial cloth were preferred by hens on the range, but these may not be sufficient to attract more hens outside during intense sunlight and hot climatic conditions.

Abstract: Extreme sunlight might be aversive to free-range laying hens, discouraging them from going outside. Range enrichment with artificial shelters may protect hens from sunlight and increase range use. The preferences of 34-40-week-old Hy-Line Brown laying hens for artificial shelters were assessed by counting the number of hens under three densities of individual shelters (three replicates/density) from video recordings for 14 to 17 days for two flocks. The artificial shelters used shade cloth marketed as blocking 50\%,70\%, and 90\% of ultraviolet light, although other sunlight wavelengths were also reduced. Different sunlight spectral irradiances (ultraviolet radiation $\left(\mathrm{UV}_{\mathrm{AB}}\right)$ (288-432 nm), photosynthetically active radiation (PAR) $(400-700 \mathrm{~nm})$, and total solar radiation (TSR) (285 nm-3000 nm), ambient temperature, and relative humidity were recorded with an on-site weather station. There was a significant interaction between sunlight-filtering shelter and time of day (both Flocks, $p<0.0001$ ), i.e., hens preferred shelters with the highest amount of sunlight-filtering at most time points. Regression models showed that the most variance in shelter use throughout the day resulted from the ambient temperature in both flocks, while sunlight parameters had different degrees of effect depending on the shelter type and flock. However, fewer hens under the shelters during the midday period suggest that during periods of intense sunlight, hens prefer to remain indoors, and artificial structures might not be sufficient to attract more hens outside.

Keywords: Australia; chicken; free-range; preference; radiation; range enrichment; shelter; ultraviolet 


\section{Introduction}

The important positive attributes of free-range (including organic) layer farming are the birds' access to an outdoor range, exposure to natural daylight (sunlight), ability to move freely, increased space to better regulate social interactions, and opportunities for expression of natural behaviours [1,2]. Free-range systems may also have some potential risks such as parasitic infections [3], increased disease exposure [4], heat stress [5], and predation [6,7]. However, welfare benefits such as reduced plumage damage and reduced footpad dermatitis can be seen in individuals that range more [8,9]. The number of hens using the range in the first few weeks following the opening of the pop holes is typically low which gradually increases upon adaptation to the outdoor environment $[10,11]$. However, a range of external factors impact the daily outdoor range use of hens, even after acclimatisation, including weather conditions [12-14], season [15], time of day [16,17], and range enrichments $[18,19]$. Sometimes, hens may hesitate to venture outside or only use certain areas of the range closer to the pop holes [16,20-22]. The distribution of hens on the range can depend on range features such as vegetation and other enrichments [17,22]. A lower use of the outdoor range at the flock level may lead to increased feather and injurious pecking $[23,24]$ or crowding of hens closer to the shed may cause smothering problems leading to bird mortality [25].

The outdoor range needs to be attractive to increase use by hens, i.e., offering different kinds of natural or artificial shelters and/or shades within the range $[10,18,26]$. These shelters may increase hens' ranging by serving as protection from predators $[27,28]$ or diffusing intense sunlight $[17,29]$. Laying hens might exhibit preferences for specific types of natural shelter options [30] as their ancestors were accustomed to dense vegetation. However, for range areas that may not have established vegetation, artificial shelters can provide protection to increase range usage and/or improve range use distribution. The exact features of these artificial shelters are likely to impact the extent to which hens use them $[17,29]$ and the most preferred features need to be better understood.

Artificial shelters that provide protection from sunlight may be particularly important for free-range hens in climates with more extreme sunlight conditions such as those experienced in Australia during the summer months. The sunlight spectrum contains all forms of ultraviolet (UV) radiation: UVA (315-400 nm), UVB (280-315 nm), and UVC (100-280 nm), of which only UVA and UVB reach the earth's surface. Hens can visually perceive UVA and UVB has a physiological effect on the synthesis of vitamin $\mathrm{D}_{3}$ in featherless skin [31]. However, high intensities and/or overexposure of UV radiation may have damaging effects [32,33], and, thus, hens might avoid direct sunlight at its most intense. Intense sunlight can also be visibly bright where the photosynthetically active radiation (PAR) wavelengths (400-700 $\mathrm{nm}$ ) may be visually aversive and infrared wavelengths $(>700 \mathrm{~nm})$ are associated with heat. Different sunlight wavelengths as well as associated ambient climatic temperature and humidity variables may all impact the motivation of hens to use artificial shelters.

Behaviourally, studies in both free-range layers and meat chickens show that birds range more and are more active during the early morning and late afternoon periods compared to around midday $[16,22,34]$. Previous studies assessing shelter preferences on commercial farms within Australia have shown hens preferred higher density (\% of UV filtering) shade cloth structures that filtered the most UV radiation [17] although preferences varied with time of day [29]. Hens also preferred artificial horizontal structures including those with one vertical side rather than vertical shelters alone [29]. However, shelter height, orientation, and cover density were all factors that affected hen preferences [29]. These studies to date highlight the complexity around optimal artificial shelter design. Further confirmation of hen preferences for artificial shelter cloth densities in relation to different sunlight wavelengths and ambient climatic variables is needed for optimising free-range systems in hot climates.

This study was conducted to assess the use by hens of different sunlight filtering shade cloth shelters in relation to different sunlight wavelengths on the range of a commercial 
free-range laying hen farm in Australia. The study hypothesised that hens would prefer the shelters that blocked a greater amount of sunlight, particularly when there was high sunlight intensity.

\section{Materials and Methods}

\subsection{Animals and Husbandry}

The study was conducted using two individual flocks (Flock-A, and Flock-B) at a single commercial free-range laying hen farm (comprised of multiple sheds and associated range areas) during the summer months (December 2020 to March 2021) in Queensland, Australia. Both flocks, comprising approximately 20,000 Hy-Line Brown laying hens each were studied from 34 to 40 weeks of age. The birds were from the same hatchery and reared indoors for 16 weeks (10-15 Lux) with the same resources, feed, and housing management as per the national laying hen guidelines [35] before shifting into the free-range facility. From 16 to 20 weeks, the hens were housed inside the indoor aviary with standard farm management protocols and resource access as per the national laying hen guidelines [35] and artificial lighting of approximately 70 Lux. At 20 weeks of age, hens were provided range access via pop holes (09:00-20:00 h). Hens were given 14 weeks of range acclimation before the study commenced.

\subsection{Study Sites}

The two study sites within the larger farm property each had distinct land layout and vegetation within the range but identical resources inside the sheds and the same management practices. Both sites had an indoor shed, which was longitudinal in the east-west position with an outdoor range at both the north and south face. Hens within the shed could only access the range on either the north or south face due to an internal shed division, thus each shed actually contained 40,000 hens total. The south side of each shed was used for this study. The indoor sheds included an aviary system, furnished with feeders, drinkers, nest boxes and perches. Feed and water were provided ad libitum inside the shed only. The base of the shed sidewalls $(0.62 \mathrm{~m})$ was made from solid materials (poly panel) and the upper parts were covered by curtains up to the ceiling. The indoor shed temperature and relative humidity were maintained both mechanically by lowering and raising the curtains and automatically with fans throughout the study periods. When the curtains were raised (between 23 and $29^{\circ} \mathrm{C}$ ), sunlight could enter the barn, although the shed was positioned so this was minimised during the summer months. Each of the indoor sheds measured $120 \mathrm{~L} \times 20 \mathrm{~W} \times 8 \mathrm{~m} \mathrm{H}$ with an indoor stocking density of 9 hens $/ \mathrm{m}^{2}$. The outdoor stocking density was 1500 hens/ha (equivalent to 0.15 hens $/ \mathrm{m}^{2}$ ). Pop-holes for range access were $0.55 \mathrm{~m}$ in height and located in the sidewalls. There was a total of 14 pop holes $(6 \mathrm{~m} \mathrm{~L} \times 0.62 \mathrm{~m} \mathrm{~W})$ on each side, but typically, only half were opened for the full shed length. The range area adjacent to the shed wall $(2.5 \mathrm{~m}$ length $)$ was covered with compact gravel, then the immediate range area ( $12 \mathrm{~m}$ length) was covered with heavy weed fabric, followed by approximately $25 \mathrm{~m}$ length of uncovered (dirt) area, and the rest of the range was covered with grass. The total range area was approximately 13 hectares in size and thus the grassed area was expansive but typically few hens were observed in the farthest range areas (producer communication to DLMC, 2020). A number of trees were establishing within the range area, planted at varying distances from the shed past the gravel and fabric-covered areas (Figure 1). The boundaries of the range area were wire fences. During the observation periods, the daylight hours in the study sites were 04:57-18:51 $\mathrm{h}$ (at the beginning) and 05:14-18:54 $\mathrm{h}$ (at the end) for Flock-A, and 05:29-18:47 $\mathrm{h}$ (at the beginning) and 05:46-18:28 $\mathrm{h}$ (at the end) for Flock-B. The average minimum and maximum outdoor ambient temperatures in Flock-A were recorded as $24.1 \pm 0.10{ }^{\circ} \mathrm{C}$ and $26.6 \pm 0.10{ }^{\circ} \mathrm{C}$ respectively, and average relative humidity was $51.4 \pm 0.27 \%$; in Flock- $\mathrm{B}$, the average minimum and maximum outdoor ambient temperatures were recorded as $24.0 \pm 0.1{ }^{\circ} \mathrm{C}$ and $27.3 \pm 0.11{ }^{\circ} \mathrm{C}$ respectively, and average relative humidity was $49.3 \pm 0.17 \%$. 


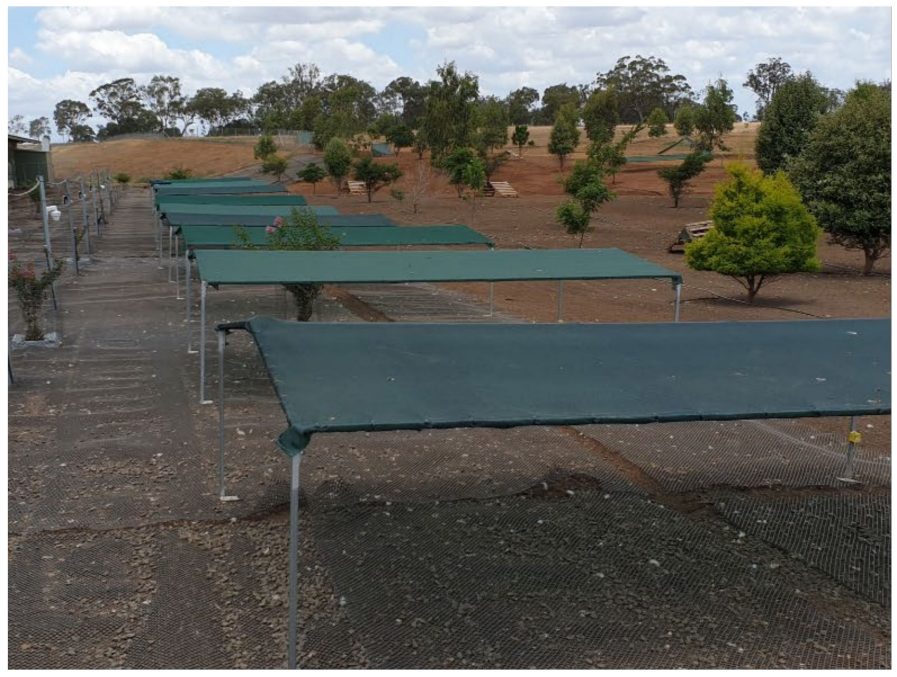

(a)

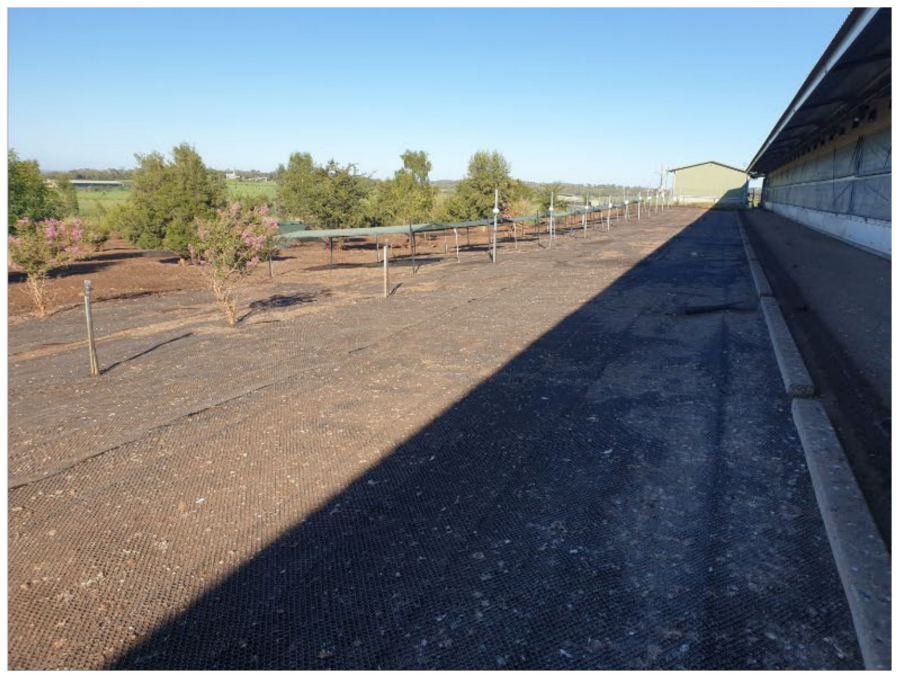

(b)

Figure 1. Experimental set-up in two different sheds of a commercial free-range farm: (a) Flock-A, and (b) Flock-B.

\subsection{Experimental Set-Up}

To test the preferences of hens for shade cloth shelters of different densities, three types of shade cloth shelters with three replicates each were used: (i) 50\% UV block (Coolaroo, 484866, Shade cloth, Rainforest), (ii) 70\% UV block (Garden Shield, SC303610CG, HDPE, Cottage Green where supplier labelling indicated 30\% UV block but controlled testing showed it was actually $70 \%$ UV block), and (iii) $90 \%$ UV block (Coolaroo, 486921, Shade cloth, Rainforest) (Figure 1).

The UV filtering percentages of the treatment shelter cloths were confirmed using an Ocean Insight Flame-S-XR1 Spectroradiometer (200-1025 nm; Quark Photonics, Melbourne, VIC, Australia) set with an integration time of $180,000 \mu$ s and integration range from 280-1000 nm (Figure 2). Measurements were taken at a distance of $20 \mathrm{~cm}$ with each type of shade cloth placed over a set of three Exo Terra ${ }^{\circledR}$ (Rolf C. Hagen, Montreal, QC, Canada) pet reptile bulbs (Reptile UVB200, 25W, PT2341) used as a standard, controlled source of UV radiation. Although the shade cloths are marketed as blocking UV radiation, they also filtered out solar radiation in the visible spectrum (Figure 2). Each shelter $(4 \mathrm{~m} \mathrm{~L} \times 3 \mathrm{~m} \mathrm{~W} \times 1 \mathrm{~m} \mathrm{H})$ was positioned in a straight line parallel with the shed $10.5 \mathrm{~m}$ away from the pop holes. This distance was selected to avoid the shadow of the shed and to entice the hens farther out onto the range. Shelters were placed $3 \mathrm{~m}$ apart following the repeating pattern of $90 \%, 70 \%$, and $50 \%$ UV block shade cloth in Flock-A and 70\%, $90 \%$, and 50\% UV block shade cloth in Flock-B (Figure 1). The structure of the shelter was made of galvanised steel and shade cloth was stretched tight over the frame to minimise its movement in the wind with a small apex along the centre. Temperature and humidity loggers (Tinytag Plus 2, TGP-4500; Gemini Data Loggers Ltd., West Sussex, UK) were placed under each shelter on the rear left post at $300 \mathrm{~mm}$ height with automated logging at 15 min intervals. The position of these loggers resulted in them sometimes being shaded and sometimes being under direct sunlight, depending on the position of the sun. A high-resolution security camera system (Hikvision DS-7608NI-I2-8P CCTV NVR Recorder) was installed with a camera (Hikvision DS-2CD2355FWD-I2 CCTV 6MP Turret cameras) on a stand $1.6 \mathrm{~m}$ in front of each shelter to capture the entire shelter and the shadows that were cast during the day (Figure S1). Each IP camera was individually cabled back to a small enclosure mounted within the range that contained a Hikvision Ethernet POE Switch (Model DS-3e0109P-E(C)) that powered the cameras as well as a set of NanoBeam ${ }^{\circledR}-\mathrm{ac}^{\prime} \mathrm{s}$ (model NBE-5AC-Gen2; Ubiquiti Inc., New York, NY, USA) that wirelessly routed the cameras back to the NVR system set up in the site office. An MEA weather station (Green 
Brain, 41 Vine Street, Magill, SA, Australia) was set-up on the respective farm site for recording sunlight and climatic variables and recorded weather data every 15 min over the study periods. The weather station was mounted on a post (user supplied) at a height of $1 \mathrm{~m}$ (height as instructed by the manufacturer) and included different sensors (UV3pAB UV sensor (288-432 nm), QS5 PAR pyranometer (400-700 nm), and SR-05 pyranometer (285-3000 $\mathrm{nm})$ ) for recording sunlight variables including ultraviolet radiation $\left(\mathrm{UV}_{\mathrm{AB}}\right)$ $\left(\mathrm{W} / \mathrm{m}^{2}\right)$, photosynthetically active radiation (PAR) $\left(\mu \mathrm{mol} / \mathrm{m}^{2} / \mathrm{s}\right)$, and total solar radiation (TSR) $\left(\mathrm{W} / \mathrm{m}^{2}\right)$, respectively. The TSR included $\mathrm{UV}_{\mathrm{AB}}, \mathrm{PAR}$ and infrared (IR) wavelengths and was used to extract IR $(700 \mathrm{~nm}-3000 \mathrm{~nm})\left(\mathrm{W} / \mathrm{m}^{2}\right)$. Additionally, an air temperature and relative humidity sensor recorded the ambient temperature $\left({ }^{\circ} \mathrm{C}\right)$, relative humidity $(\%)$, barometric pressure (mBar), dew point $\left({ }^{\circ} \mathrm{C}\right)$, voltage $(\mathrm{V})$, and vapor pressure deficit $(\mathrm{kPa})$. As the study was primarily focused on the hen preferences for different shelters relative to sunlight variables, only solar radiation spectra, air temperature, and relative humidity data were considered in the final analyses.

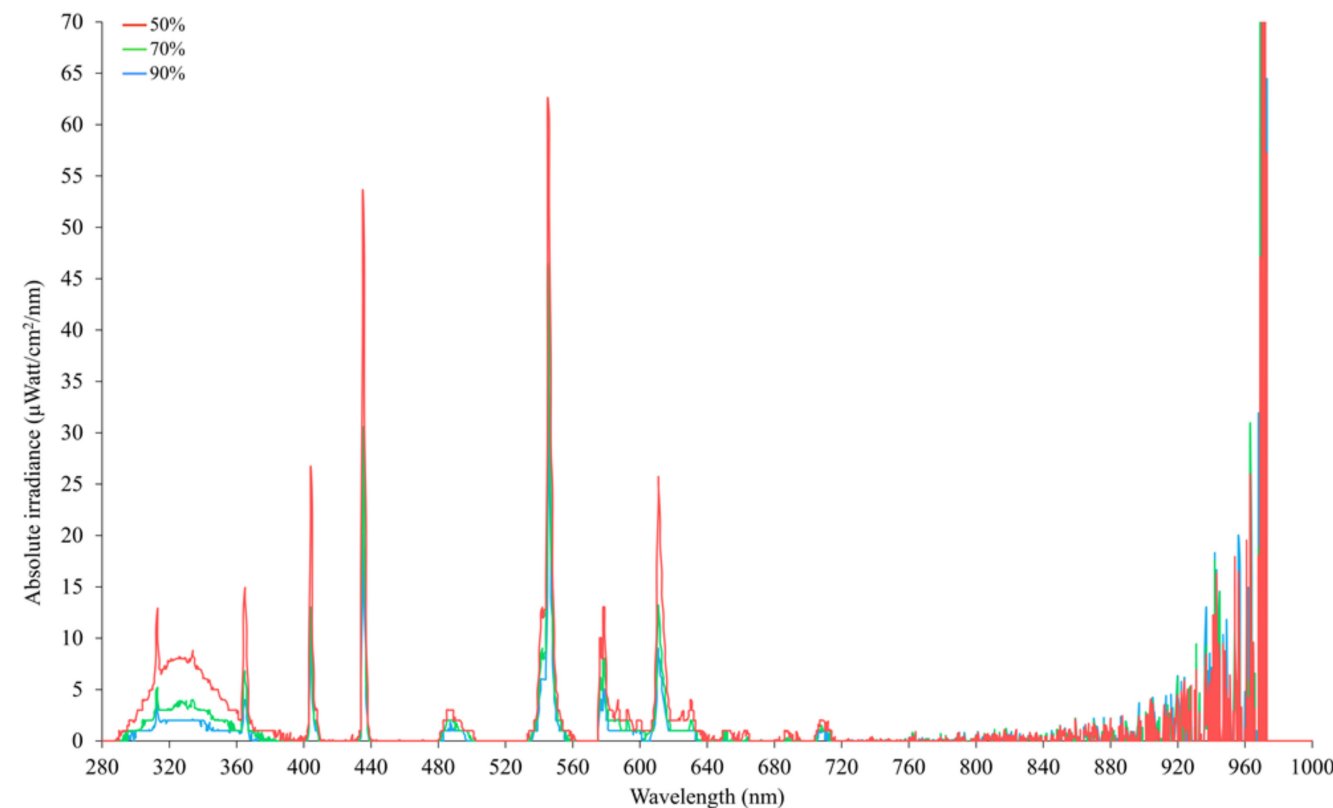

Figure 2. Spectral irradiance under different UV-filtering shade cloths (50\%, 70\%, and $90 \%$ UV block) as measured by an Ocean Insight Flame-S-XR1 Spectroradiometer at a distance of $20 \mathrm{~cm}$ with each type of shade cloth placed over a set of three Exo Terra ${ }^{\circledR}$ (Rolf C. Hagen, Montreal, QC, Canada) pet reptile bulbs (Reptile UVB200, 25W, PT2341).

\subsection{Observations and Data Collection}

The shelters were installed when the hens were 34 weeks of age with 2 weeks allowed for habituation to the range shelters before the study observations began. Recording was continuous during daylight hours for approximately 5 weeks for Flock-A and 4 weeks for Flock-B. Due to temporary failures in video recording, a total of 14 days videos for Flock-A and 17 days for Flock-B were analysed and these days were not consecutive within the recording period. For assessing shelter preferences, image snapshots from video records were taken at $30 \mathrm{~min}$ intervals from $30 \mathrm{~min}$ after pop hole opening (i.e., 09:30) until just before sunset (i.e., 18:30). The images were imported into Image-J 1.53a software (Wayne Rasband, National Institute of Health, MA, USA) and an observer counted the number of hens both under the individual shelters and on top of the shelters. When there were two observers, both researchers discussed the counts on common snapshots to ensure agreement. Observers were not blinded to the shade cloth densities given the differing darkness of the shadows cast by the shelters, but each observer conducted counts for all densities to minimise observer bias for a specific treatment density. On sunny days, the area for counting the hens under the shelter was defined by the shadow that the shelter 
cast (the exact position of the shadow varied throughout the day) (Figure S1). On cloudy days without a prominent shadow, the counting area was considered as the area directly underneath the shelter frame. If the individual hens could not be clearly identified due to crowding under the shelter, the number of hens was estimated in the group by counting the birds within a certain area and then multiplying that number by the counted area (this occurred on 41 occasions out of 5301 observations for both flocks).

\subsection{Data and Statistical Analyses}

All observations for each flock were analysed separately. A combined total of $5301 \mathrm{ob}-$ servations were made over the 14-day period in Flock-A (2394 observations), and 17-day period in Flock-B (2907 observations) to count both the hens underneath and on top of the shelters. The number of hens counted in each observation was matched with the corresponding weather parameters during the 15-min period directly prior to the observation time point. Weather parameters included the $\mathrm{UV}_{\mathrm{AB}}, \mathrm{PAR}, \mathrm{TSR}$, ambient temperature and relative ambient humidity, and temperature and relative humidity readings from the loggers underneath the shelters. The hen count data contained a considerable number of ' 0 ' values (when no hens were under or on top of the shelters) and were not normally distributed, thus these data were $\log (x+1)$ transformed to include the ' 0 ' values in the analyses as well as to approach data normality. To test the preferences of the hens to be underneath the shelters during the study period, data were analysed using JMP ${ }^{\circledR} 14.0$ (SAS Institute, Cary, NC, USA) with $\alpha$ level set at 0.05. General linear mixed models (GLMM) were applied with the different UV-filtering percentages, time of day, and their interaction included as fixed effects and shelter replicate nested within UV-filtering percentage as a random effect. A separate model with the same parameters was fitted to assess the preferences of the hens to be on top of the shelters. While the different sunlight filtering percentages were not predicted to affect hen preferences on top of the shelters, there may have been social influences if shelters with more hens underneath them, also had more hens located on top. The studentised model residuals were visually inspected for confirming homoscedasticity. Where significant differences were present, post hoc Student's t-tests were applied to the least squares means with Bonferroni corrections to the $\alpha$ level to account for multiple post-hoc comparisons. The means of the temperature and relative humidity underneath the shelter were plotted, along with the mean ambient temperature and humidity during the day. However, these data were not statistically analysed as their positioning on the rear leg of the shelters resulted in the loggers sometimes being under direct sunlight which meant that they were not always an accurate measure of the temperature experienced by a hen when under the shaded part of the shelter.

To investigate the effects of sunlight variables on shelter use by hens during the day (presence under the shelter regardless of shelter type), an overall linear regression model was constructed for each flock using a summarised dataset where values within each UVfiltering percentage were averaged across all three replicates for each time point for each day $(n=798$ per UV-filtering percentage in Flock-A, and $n=969$ per UV-filtering percentage in Flock-B). Before setting the model, IR spectrum values were extracted from the TSR readings by subtracting $U_{\mathrm{AB}}$ and PAR. A conversion value $\left(\mu \mathrm{mol} / \mathrm{m}^{2} / \mathrm{s}\right.$ to $\left.\mathrm{W} / \mathrm{m}^{2}\right)$ as described by Thimijan and Heins [36], was applied to the PAR readings so all measures were in the same units for calculating the IR values. The number of hens underneath the UV-filtering shelters were included as the dependent variable, whereas sunlight variables $\left(\mathrm{UV}_{\mathrm{AB}}, \mathrm{PAR}\right.$ and IR), ambient temperature, and relative ambient humidity were included as independent variables in the model. Prior to running the model in R statistical software [37], the collinearity among the independent variables were checked through determination of variance inflation factors (VIF). Due to collinearity (VIF $\geq 10$ ) among the sunlight variables, the ridge regression [38] was chosen to best fit the predictors into the model using the 'lmridge' package in $\mathrm{R}$ [39]. The relative contributions of the predictors in the regression model were estimated by the R package 'relaimpo' [40]. All independent variables were initially included in the model with nonsignificant variables $(p \geq 0.10)$ 
removed through backward elimination until the model of best fit was produced based on the adjusted $\mathrm{R}^{2}$ values. To specifically determine how sunlight and weather variables may affect the use of the different shelter types, individual linear ridge regression models were performed separately for each UV-filtering percentage with the number of hens underneath included as the dependent variable, and the sunlight variables $\left(\mathrm{UV}_{\mathrm{AB}}, \mathrm{PAR}\right.$, and IR), ambient temperature, and relative ambient humidity included as independent variables. Nonsignificant variables $(p \geq 0.10)$ were removed through backward elimination. The raw values are plotted in the figures.

\section{Results}

\subsection{Shelter Preferences}

There was a significant interaction between UV-filtering shelter and time of day for hen preferences in both Flock-A $\left(\mathrm{F}_{36,2331}=3.49, p<0.0001\right)$, and Flock-B $\left(\mathrm{F}_{36,2844}=2.63\right.$, $p<0.0001$ ) (Figure 3). In general, at most observation points throughout the day, more hens were seen under the $90 \%$ UV-filtering shelters in both flocks, but at some time points their preferences were similar for all filtering percentages $(p>0.001)$ (Figure 3).

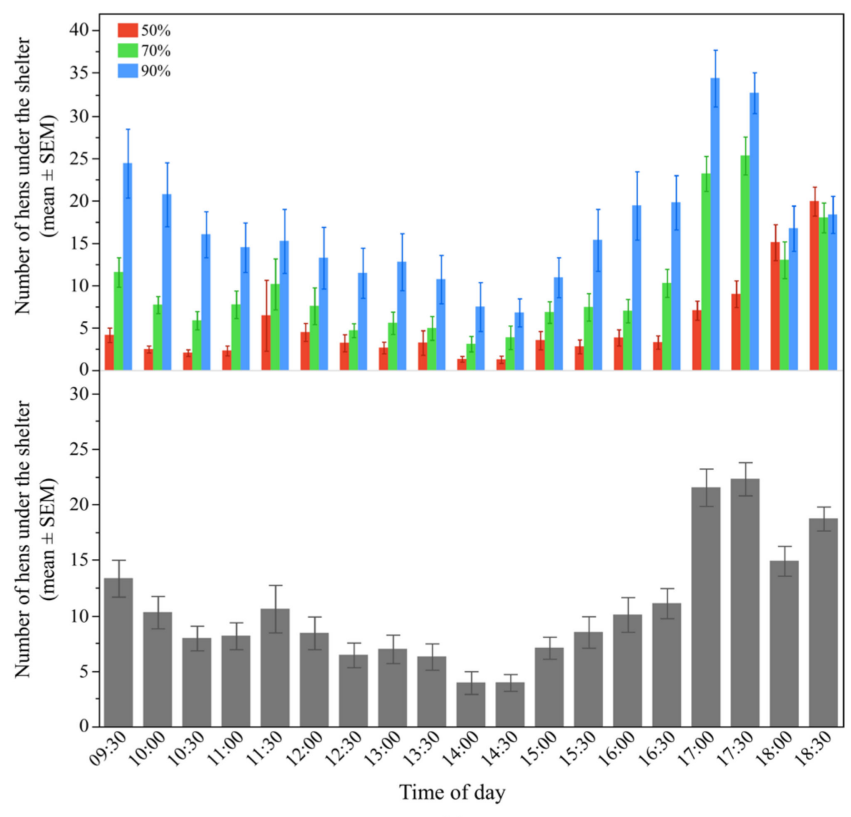

(a)

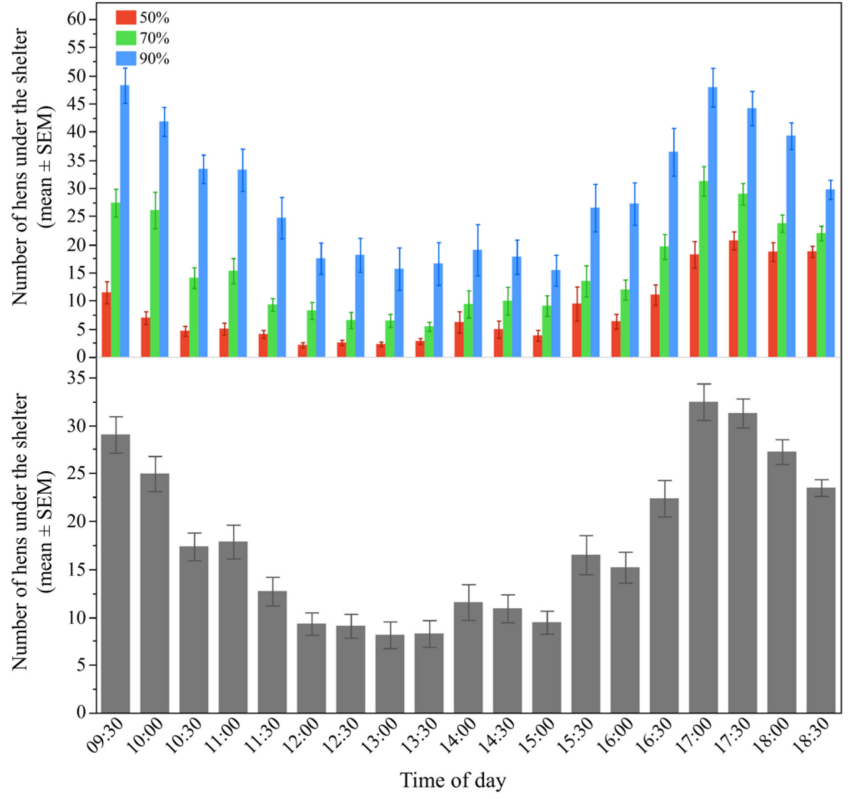

(b)

Figure 3. The mean $( \pm \mathrm{SEM})$ number of hens underneath the shelters during the day: (a) Flock-A: with different UV-filtering percentages (50\%, 70\%, and 90\%) (top), under all UV-filtering shelters (bottom); (b) Flock-B: with different UV-filtering percentages (50\%, 70\%, and 90\%) (top), under all UV-filtering shelters (bottom). Note the different Y-axis scales between Flock-A and Flock-B. Raw values are presented with analyses conducted on transformed data.

Overall, more hens were found underneath the 90\% UV-filtering shelters (LSM mean \pm SEM, Flock-A: $16.9 \pm 2.67$ hens; Flock-B: $29.1 \pm 1.52$ hens), followed by the $70 \%$ (LSM mean \pm SEM, Flock-A: $9.7 \pm 2.67$ hens; Flock-B: $15.7 \pm 1.52$ hens) then $50 \%$ UVfiltering shelters (LSM mean \pm SEM, Flock-A: $5.2 \pm 2.67$ hens; Flock-B: $8.4 \pm 1.52$ hens) in both study flocks (Flock-A: $F_{2,6}=16.25, p=0.004$, and Flock-B: $F_{2,6}=134.09, p<0.0001$ ). The use of the shelter shade by hens varied throughout the day in both Flock-A $\left(\mathrm{F}_{18,2331}=44.64\right.$, $p<0.0001)$ and Flock-B $\left(\mathrm{F}_{18,2844}=75.11, p<0.0001\right)$, with peaks in the morning and in the late afternoon, compared to the midday $(p<0.003)$ (Figure 3$)$.

In contrast, there was no significant interaction between UV-filtering shelter and time of day for the number of hens on top of the shelters in Flock-A $\left(F_{36,2331}=0.89, p=0.65\right)$; whereas a significant interaction was found in Flock-B $\left(\mathrm{F}_{36,2844}=2.68, p<0.0001\right)$ (Figure 4). 
In Flock-B, throughout the day, there was a general pattern of more hens on top of the $90 \%$ UV-filtering shelters in the morning and late afternoon relative to both the $50 \%$ and $70 \%$ shelters $(p>0.001)$ (Figure 4).

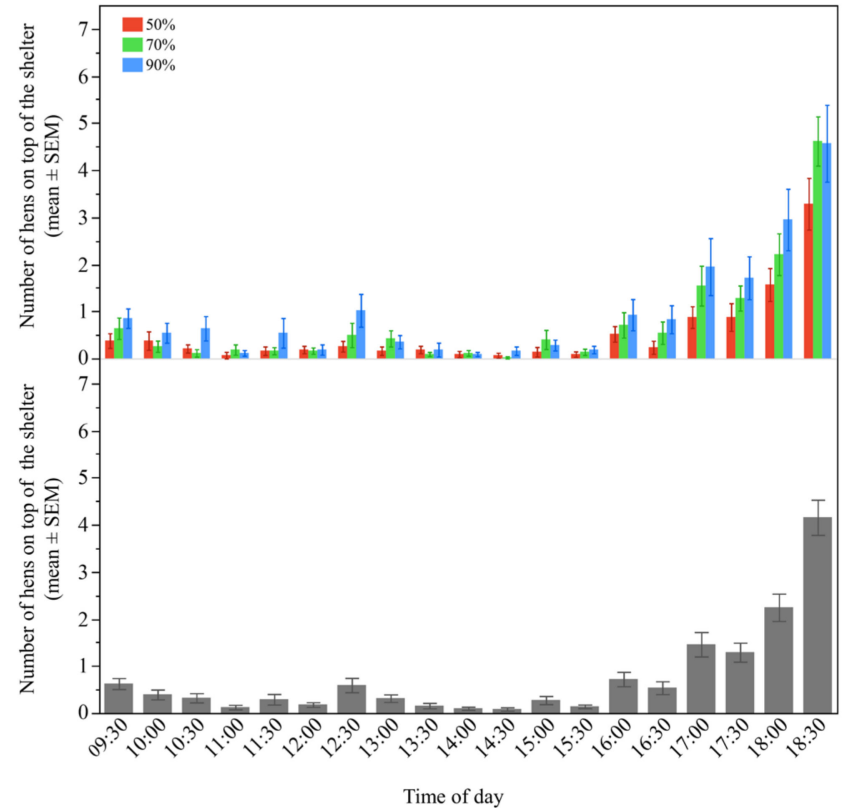

(a)

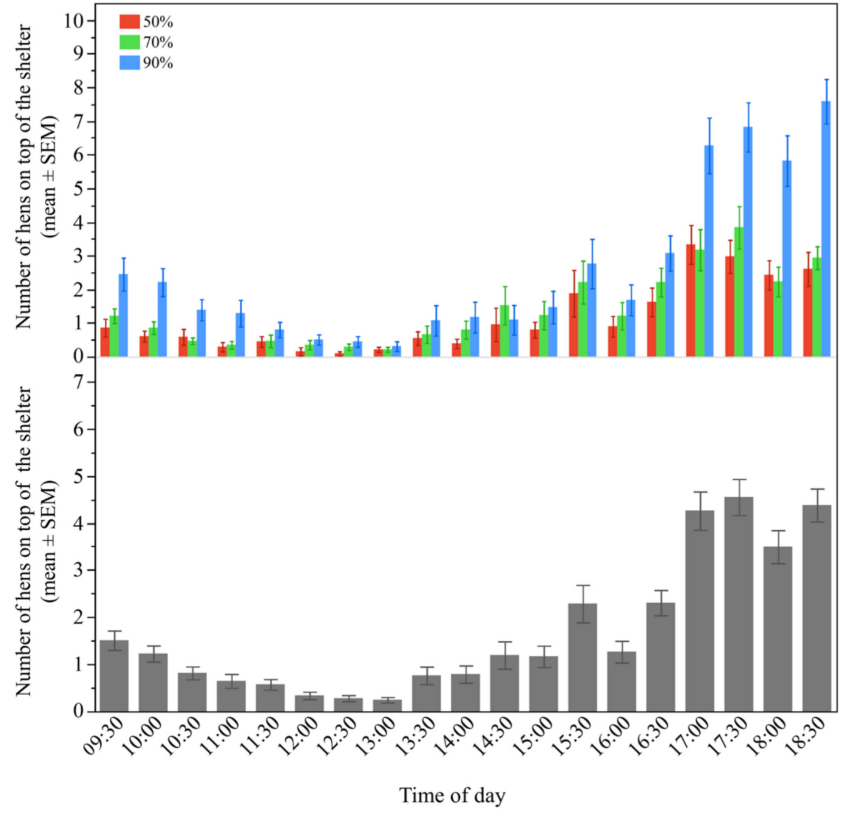

(b)

Figure 4. The mean $( \pm \mathrm{SEM})$ number of hens on top of the shelters throughout the day: (a) FlockA: with different UV-filtering percentages (50\%, 70\%, and 90\%) (top), on all UV-filtering shelters (bottom); (b) Flock-B: with different UV-filtering percentages (50\%, 70\%, and $90 \%$ ) (top), on all UV-filtering shelters (bottom). Note the different Y-axis scales between Flock-A and Flock-B for the top graphs. Raw values are presented with analyses conducted on transformed data.

Overall, there was no difference for the number of hens on top of the shelters between the different UV-filtering percentages in Flock-A (LSM mean \pm SEM, 50\%: $0.52 \pm 0.18$, $\left.70 \%: 0.75 \pm 0.18,90 \%: 0.96 \pm 0.18, \mathrm{~F}_{2,6}=1.37, p=0.32\right)$, but the time of day had an effect on the number of hens throughout the day $\left(\mathrm{F}_{18,2331}=41.78, p<0.0001\right)$, with a gradually increasing trend after 17:00 compared to the rest of the day $(p<0.003)$ (Figure 4$)$. In Flock-B, more hens were found on top of the $90 \%$ UV-filtering shelter with no differences between the $50 \%$ and $70 \%$ shelters (LSM mean \pm SEM, 50\%: $1.14 \pm 0.24,70 \%: 1.38 \pm 0.24,90 \%$ : $\left.2.54 \pm 0.24, \mathrm{~F}_{2,6}=9.14, p=0.02\right)$. Time of day had an effect on the number of hens on top of the shelters $\left(\mathrm{F}_{18,2844}=36.56, p<0.0001\right)$ with more hens observed in the late afternoon $(p<0.003)$ (Figure 4).

The temperature and humidity loggers underneath the shelters were intended to provide measurements on ambient conditions the hens may have been experiencing. However, the placement of loggers at hen eye height on one of the rear posts of the shelters resulted in the loggers sometimes being under direct sunlight and sometimes being under the shelter shade. Figure 5 displays the temperature and relative humidity readings under each shelter type relative to the ambient temperature and relative ambient humidity readings obtained from the weather station which was placed $1 \mathrm{~m}$ above ground. The temperature under the shelters was higher than the ambient temperature, whereas relative humidity was lower than the relative ambient humidity during the daytime (Figure 5). The temperatures and relative humidity under the different shelter types were visually similar, but these data were not statistically analysed, as the loggers did not capture data as originally intended. 


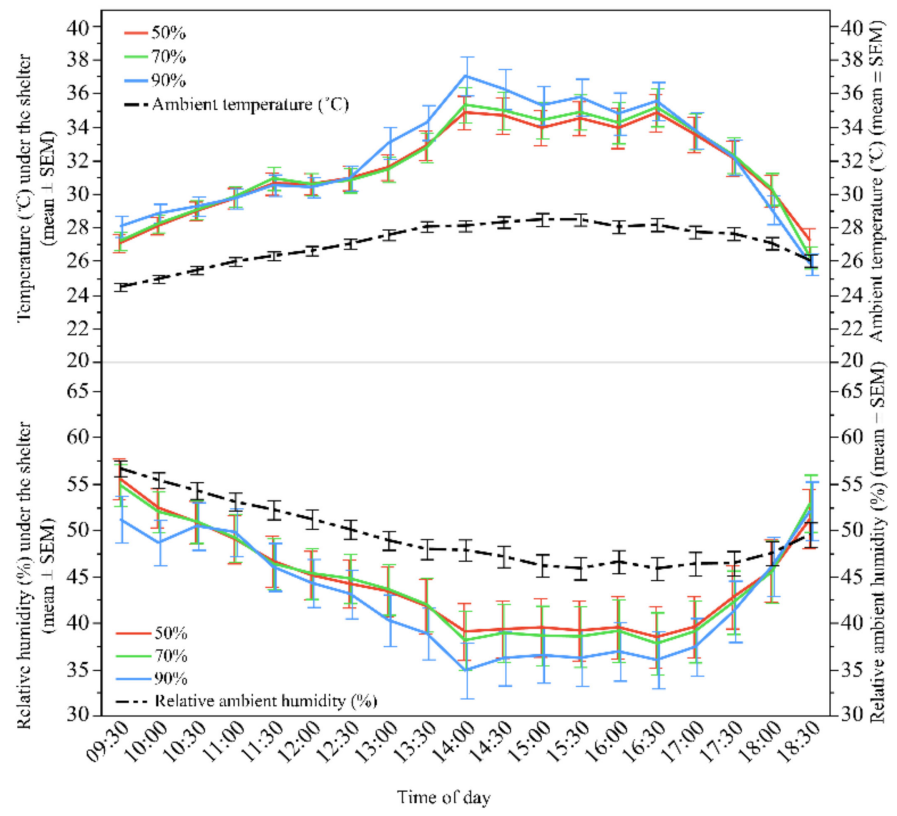

(a)

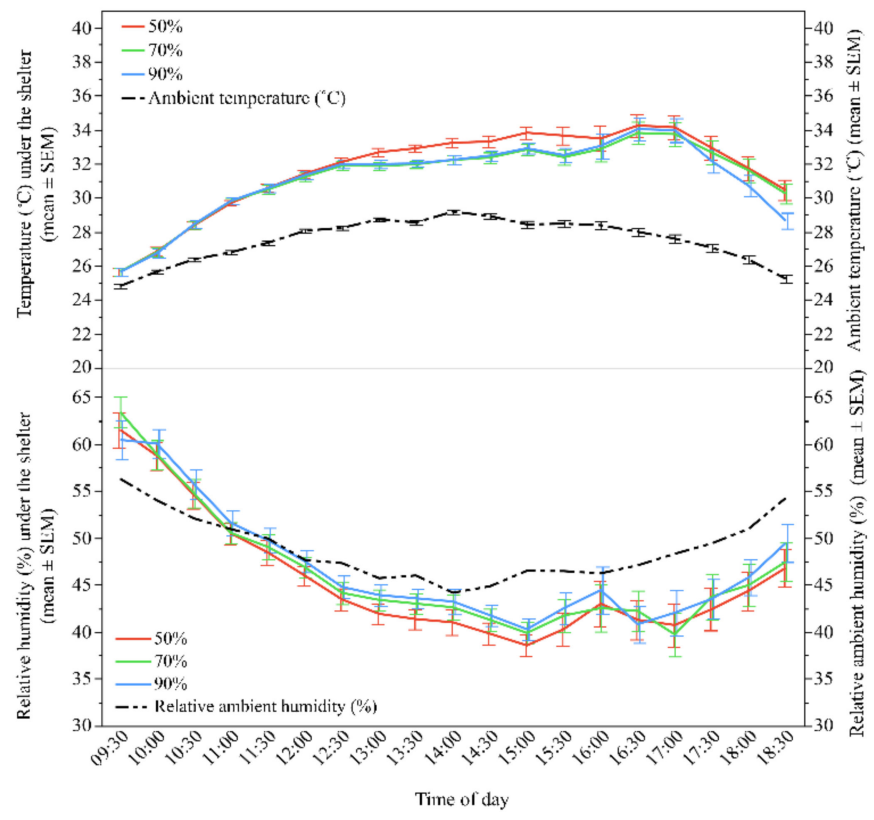

(b)

Figure 5. The mean $( \pm S E M)$ temperature and relative humidity throughout the day underneath the shelters of different UV-filtering percentages (50\%, 70\%, and 90\%) and ambient temperature and relative humidity: (a) Flock-A: temperature under the shelters and ambient temperature (top), relative humidity under the shelters and relative ambient humidity (bottom); (b) Flock-B: temperature under the shelters and ambient temperature (top), relative humidity under the shelters and relative ambient humidity (bottom). Raw values are presented with analyses conducted on transformed data.

\subsection{Sunlight Effects}

A ridge regression model for each flock was performed to investigate the relationship between the number of hens underneath the shelters across all the UV-filtering percentages and the sunlight variables, ambient temperature and relative ambient humidity. The best-fit model results are presented in Table 1. In Flock-A, the model accounted for $34.21 \%$ of the variance in the use of all the UV-filtering shelters throughout the day. The ambient temperature, $\mathrm{UV}_{\mathrm{AB}}, \mathrm{IR}$, and relative ambient humidity contributed significantly to the model $\left(\mathrm{F}_{3.35,794.24}=120.50, p<0.0001\right)$. However, all these predictors had a negative correlation with the number of hens under the shelters throughout the day (Table 1).

In Flock-B, the model accounted for $35.77 \%$ of the variance in the number of hens under the shelters with respect to sunlight and weather variables considered within the model. The majority of the variance was explained by the ambient temperature $(49.01 \%)$, however IR, $\mathrm{UV}_{\mathrm{AB}}$ and PAR also significantly contributed to the model $\left(\mathrm{F}_{2.68}, 965.98=146.64\right.$, $p<0.0001$, Table 1 ). The ambient temperature, $\mathrm{UV}_{\mathrm{AB}}$, and IR were negatively correlated, and PAR was positively correlated with the number of hens underneath the shelters (Table 1).

The separate ridge regression models for each UV-filtering percentage showed differences in the relative impacts of the sunlight and weather variables on the number of hens underneath the shelters. For the $50 \%, 70 \%$, and $90 \%$ UV-filtering shelter preferences, both sunlight and weather variables accounted for $51.71 \%$ (Flock-A: $\mathrm{F}_{2.79,263.03}=108.58, p<0.0001$ ) and $57.94 \%$ (Flock-B: $\mathrm{F}_{2.53,320.19}=156.77, p<0.0001$ ) of the variance for the $50 \%$ shelters, $40.35 \%$ (Flock-A: $\mathrm{F}_{2.79,263.03}=71.33, p<0.0001$ ) and 44.29\% (Flock-B: $\mathrm{F}_{2.68,319.98}=71.26$, $p<0.0001$ ) of the variance for the $70 \%$ shelters, and $35.16 \%$ (Flock-A: $\mathrm{F}_{3.08,262.54}=51.13$, $p<0.0001$ ) and $37.77 \%$ of the variance (Flock-B: $\mathrm{F}_{2.68,319.98}=56.45, p<0.0001$ ) for the $90 \%$ shelters (Table 2). 
Table 1. Two ridge regression analyses (ridge parameter, $\mathrm{k}=0.02$ ) on the number of hens under the shelter throughout the day. Only variables that significantly contributed to the most parsimonious model are presented.

\begin{tabular}{|c|c|c|c|c|c|c|c|}
\hline Flock & & $\mathbf{r}^{1}$ & $\begin{array}{c}\beta \text { - Coefficient } \\
\text { (Standardised) }\end{array}$ & t-Value & $p$-Value & $\begin{array}{c}\text { Adjusted } \mathrm{R}^{2} \text { and } \\
\text { Model's } \\
\text { F-Statistics }\end{array}$ & $\begin{array}{l}\text { Relative } \\
\text { Weight of the } \\
\text { Predictors in } \\
\text { the Model }\end{array}$ \\
\hline \multirow[t]{4}{*}{ Flock-A } & \multirow{4}{*}{\multicolumn{2}{|c|}{$\begin{array}{c}\text { Ambient temperature } \\
\text { Relative ambient } \\
\text { humidity } \\
\mathrm{UV}_{\mathrm{AB}} \\
\mathrm{IR}\end{array}$}} & -0.70 & -12.61 & $<0.0001$ & \multirow{4}{*}{$\begin{array}{c}\mathrm{R}^{2} \text {-adjusted }=0.34 \\
\mathrm{~F}_{3.35,794.24}=120.50 \\
p<0.0001\end{array}$} & $33.54 \%$ \\
\hline & & & & & $<0.0001$ & & $13.86 \%$ \\
\hline & & & -0.15 & -2.17 & 0.03 & & $25.36 \%$ \\
\hline & & & -0.24 & -3.37 & 0.001 & & $27.24 \%$ \\
\hline \multirow[t]{6}{*}{ Flock-B } & \multirow{4}{*}{\multicolumn{2}{|c|}{$\begin{array}{c}\text { Ambient temperature } \\
\mathrm{UV}_{\mathrm{AB}} \\
\text { PAR } \\
\mathrm{IR}\end{array}$}} & -0.41 & -15.90 & $<0.0001$ & \multirow{4}{*}{$\begin{array}{c}\mathrm{R}^{2} \text {-adjusted }=0.36 \\
\mathrm{~F}_{2.68,965.98}=146.64 \\
p<0.0001\end{array}$} & $49.01 \%$ \\
\hline & & & -0.27 & -3.78 & $<0.001$ & & $16.88 \%$ \\
\hline & & & 0.10 & 2.07 & 0.04 & & $16.84 \%$ \\
\hline & & & -0.19 & -3.70 & $<0.001$ & & $17.28 \%$ \\
\hline & \multirow{2}{*}{\multicolumn{7}{|c|}{$\begin{array}{l}\ddagger \beta \text {-coefficients (standardised) of the predictor variables were estimated separately using the ridge regression } \\
\text { coefficient in ' } \mathrm{R} \text { ' as the original ridge package did not include the ' } \beta \text {-coefficient' value in the regression outputs. } \\
{ }^{1} \mathrm{UV}_{\mathrm{AB}} \text { (ultraviolet radiation A and B wavelengths), PAR (photosynthetically active radiation), IR (infrared } \\
\text { radiation). } \\
\text { Table 2. Multiple ridge regression analyses (ridge parameter, } \mathrm{k}=0.02 \text { ) on the number of hens under } \\
\text { different UV-filtering shelters throughout the day. Only variables that significantly contributed to the } \\
\text { most parsimonious model are presented. }\end{array}$}} \\
\hline & & & & & & & \\
\hline $\begin{array}{l}\text { UV-Filtering } \\
\text { Shelter }\end{array}$ & Flock & Predictor $^{1}$ & $\begin{array}{c}\text { B-Coefficient } \\
\text { (Standardised) }\end{array}$ & $t$-Value & $p$-Value & $\begin{array}{c}\text { Adjusted } \mathrm{R}^{2} \text { and } \\
\text { Model's } \\
\text { F-Statistics }\end{array}$ & $\begin{array}{l}\text { Relative } \\
\text { Weight of } \\
\text { the } \\
\text { Predictors in } \\
\text { the Model }\end{array}$ \\
\hline \multirow[t]{6}{*}{$50 \%$} & \multirow[t]{3}{*}{ A } & $\begin{array}{l}\text { Ambient } \\
\text { temperature }\end{array}$ & -0.59 & -7.16 & $<0.0001$ & \multirow{3}{*}{$\begin{array}{c}\mathrm{R}^{2} \text {-adjusted }=0.52 \\
\mathrm{~F}_{2.79,263.03}=108.58, \\
p<0.0001\end{array}$} & $24.62 \%$ \\
\hline & & $\begin{array}{l}\text { Relative } \\
\text { ambient } \\
\text { humidity }\end{array}$ & -0.36 & -4.42 & $<0.0001$ & & $10.52 \%$ \\
\hline & & PAR & -0.56 & -13.25 & $<0.0001$ & & $64.86 \%$ \\
\hline & \multirow[t]{3}{*}{ B } & $\begin{array}{l}\text { Ambient } \\
\text { temperature }\end{array}$ & -0.40 & -11.24 & $<0.0001$ & \multirow{3}{*}{$\begin{array}{c}\mathrm{R}^{2} \text {-adjusted }=0.58 \\
\mathrm{~F}_{2.53,320.19=156.77}, \\
p<0.0001\end{array}$} & $34.26 \%$ \\
\hline & & $\mathrm{UV}_{\mathrm{AB}}$ & -0.29 & -3.18 & $<0.01$ & & $32.43 \%$ \\
\hline & & IR & -0.28 & -3.08 & $<0.01$ & & $33.31 \%$ \\
\hline \multirow[t]{7}{*}{$70 \%$} & \multirow[t]{3}{*}{ A } & $\begin{array}{c}\text { Ambient } \\
\text { temperature }\end{array}$ & -0.77 & -8.48 & $<0.0001$ & \multirow{3}{*}{$\begin{array}{c}\mathrm{R}^{2} \text {-adjusted }=0.40 \\
\mathrm{~F}_{2.79,263.03}=71.33 \\
p<0.0001\end{array}$} & $38.52 \%$ \\
\hline & & $\begin{array}{l}\text { Relative } \\
\text { ambient } \\
\text { humidity }\end{array}$ & -0.46 & -5.11 & $<0.0001$ & & $15.64 \%$ \\
\hline & & $\mathrm{UV}_{\mathrm{AB}}$ & -0.41 & -8.87 & $<0.0001$ & & $45.85 \%$ \\
\hline & \multirow[t]{4}{*}{ B } & $\begin{array}{c}\text { Ambient } \\
\text { temperature }\end{array}$ & -0.44 & -10.63 & $<0.0001$ & \multirow{4}{*}{$\begin{array}{c}\mathrm{R}^{2} \text {-adjusted }=0.44 \\
\mathrm{~F}_{2.68,319.98}=71.26, \\
p<0.0001\end{array}$} & $45.57 \%$ \\
\hline & & $\mathrm{UV}_{\mathrm{AB}}$ & -0.33 & -2.85 & $<0.01$ & & $18.10 \%$ \\
\hline & & PAR & 0.13 & 1.66 & 0.10 & & $17.91 \%$ \\
\hline & & $\mathrm{IR}$ & -0.22 & -2.70 & 0.01 & & $18.42 \%$ \\
\hline $90 \%$ & A & $\begin{array}{l}\text { Ambient } \\
\text { temperature }\end{array}$ & -0.93 & -9.99 & $<0.0001$ & $\mathrm{R}^{2}$-adjusted $=0.35$ & $40.75 \%$ \\
\hline
\end{tabular}


Table 2. Cont.

\begin{tabular}{|c|c|c|c|c|c|c|c|}
\hline $\begin{array}{l}\text { UV-Filtering } \\
\text { Shelter }\end{array}$ & Flock & Predictor $^{1}$ & $\begin{array}{c}\text { B-Coefficient } \\
\text { (Standardised) }\end{array}$ & $t$-Value & $p$-Value & $\begin{array}{l}\text { Adjusted } \mathrm{R}^{2} \text { and } \\
\text { Model's } \\
\text { F-Statistics }\end{array}$ & $\begin{array}{c}\text { Relative } \\
\text { Weight of } \\
\text { the } \\
\text { Predictors in } \\
\text { the Model }\end{array}$ \\
\hline & & $\begin{array}{l}\text { Relative } \\
\text { ambient } \\
\text { humidity }\end{array}$ & -0.68 & -7.44 & $<0.0001$ & \multirow[t]{3}{*}{$\begin{array}{c}\mathrm{F}_{3.08,262.54}=51.13 \\
p<0.0001\end{array}$} & $18.85 \%$ \\
\hline & & PAR & 0.20 & 1.84 & 0.07 & & $19.14 \%$ \\
\hline & & IR & -0.53 & -4.92 & $<0.0001$ & & $21.26 \%$ \\
\hline & \multirow[t]{4}{*}{ B } & $\begin{array}{c}\text { Ambient } \\
\text { temperature }\end{array}$ & -0.54 & -12.28 & $<0.0001$ & \multirow{4}{*}{$\begin{array}{c}\mathrm{R}^{2} \text {-adjusted }=0.38 \\
\mathrm{~F}_{2.68,319.98}=56.45 \\
p<0.0001\end{array}$} & $71.58 \%$ \\
\hline & & $\mathrm{UV}_{\mathrm{AB}}$ & -0.31 & -2.51 & 0.01 & & $9.20 \%$ \\
\hline & & PAR & 0.24 & 2.85 & $<0.01$ & & $9.58 \%$ \\
\hline & & IR & -0.15 & -1.78 & 0.08 & & $9.63 \%$ \\
\hline
\end{tabular}

$\ddagger \beta$-coefficients (standardised) of the predictor variables were estimated separately using the ridge regression coefficient in ' $R$ ' as the original ridge package did not include the ' $\beta$-coefficient' value in the regression outputs. ${ }^{1} \mathrm{UV}_{\mathrm{AB}}$ (ultraviolet radiation $\mathrm{A}$ and $\mathrm{B}$ wavelengths), PAR (photosynthetically active radiation), IR (infrared radiation).

The ambient temperature significantly affected the preferences of the hens for each shelter type in both flocks (Flock-A: all $p<0.0001$; Flock-B: all $p<0.0001$ ) (Figure 6); this parameter was the greatest contributing factor for use of the $70 \%$ and $90 \%$ UV-filtering shelters. Temperature accounted for $38.52 \%$ and $40.75 \%$ of the variation in Flock-A for the $70 \%$ and $90 \%$ shelters respectively, and $45.57 \%$ and $71.58 \%$ of the variation in Flock-B for the $70 \%$ and $90 \%$ shelters, respectively. The results indicated that increased ambient temperature resulted in fewer hens under the shelters (Table 2).

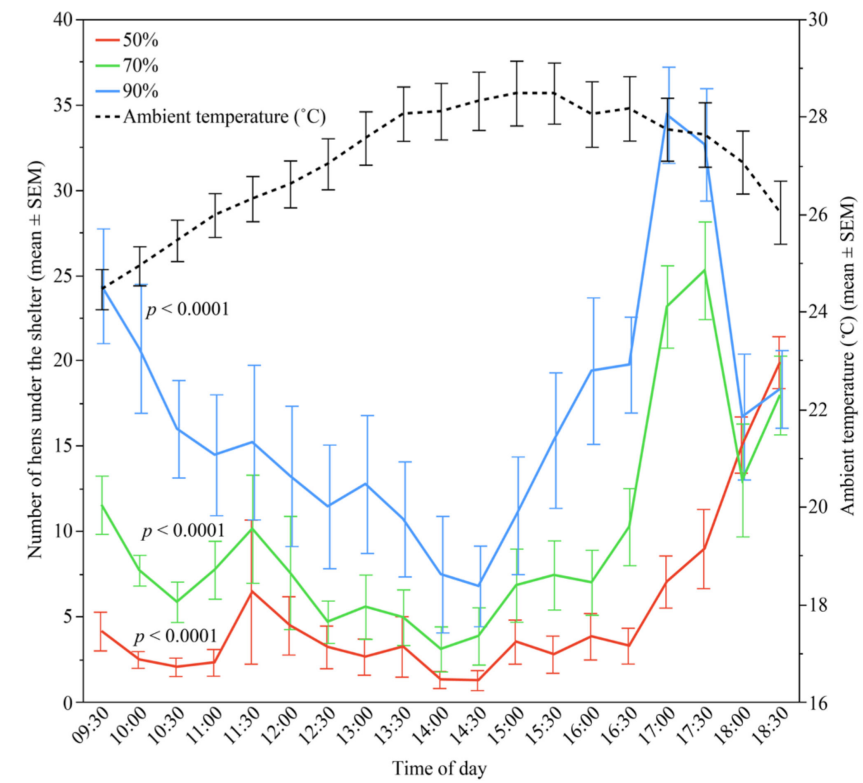

(a)

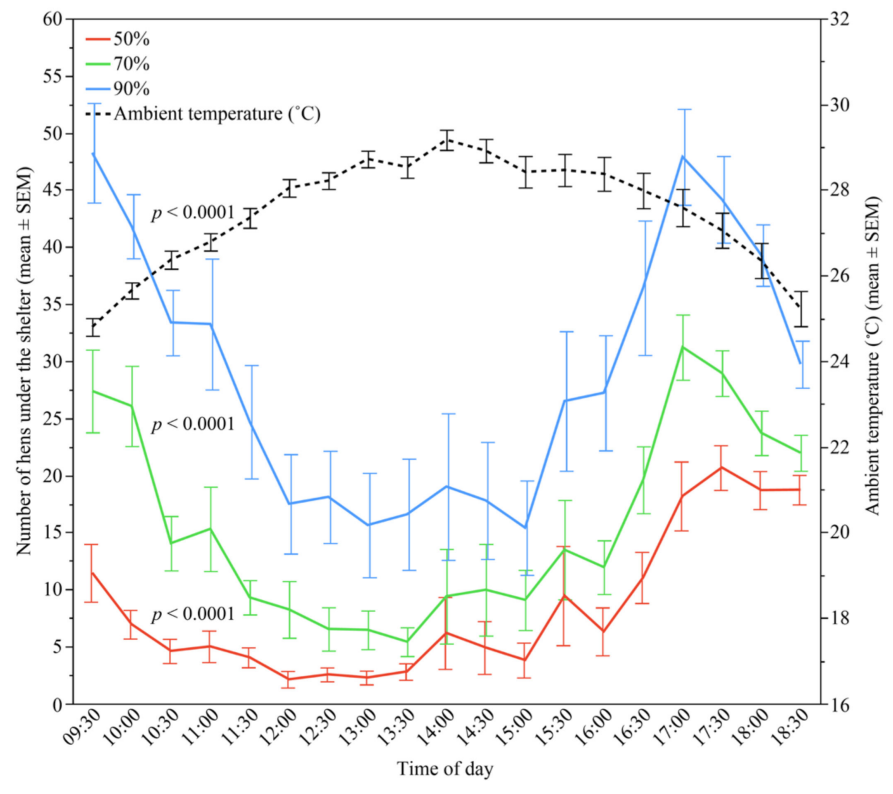

(b)

Figure 6. The mean $( \pm$ SEM) number of hens under the different UV-filtering shelters (50\%, 70\%, and $90 \%$ ) and the mean ( \pm SEM) ambient temperature throughout the day: (a) Flock-A; (b) Flock-B $(p>0.10$ indicates the variable had no significant effect and was removed from final model). Note the different Y-axis scales between Flock-A and Flock-B. Raw values are presented with analyses conducted on transformed data. 
The relative ambient humidity also significantly contributed to the preferences of the hens for each shelter type in Flock-A (all $p<0.0001$ ), but did not show an effect in Flock-B (Figure 7). However, in Flock-A, the relative contribution of the relative ambient humidity was less than $20 \%$ in the models of $50 \%, 70 \%$ and $90 \%$ UV-filtering shelters (accounting for $10.52 \%, 15.64 \%$, and $18.85 \%$ of the variation, respectively), and had a negative correlation with the number of hens under the shelters (Table 2).

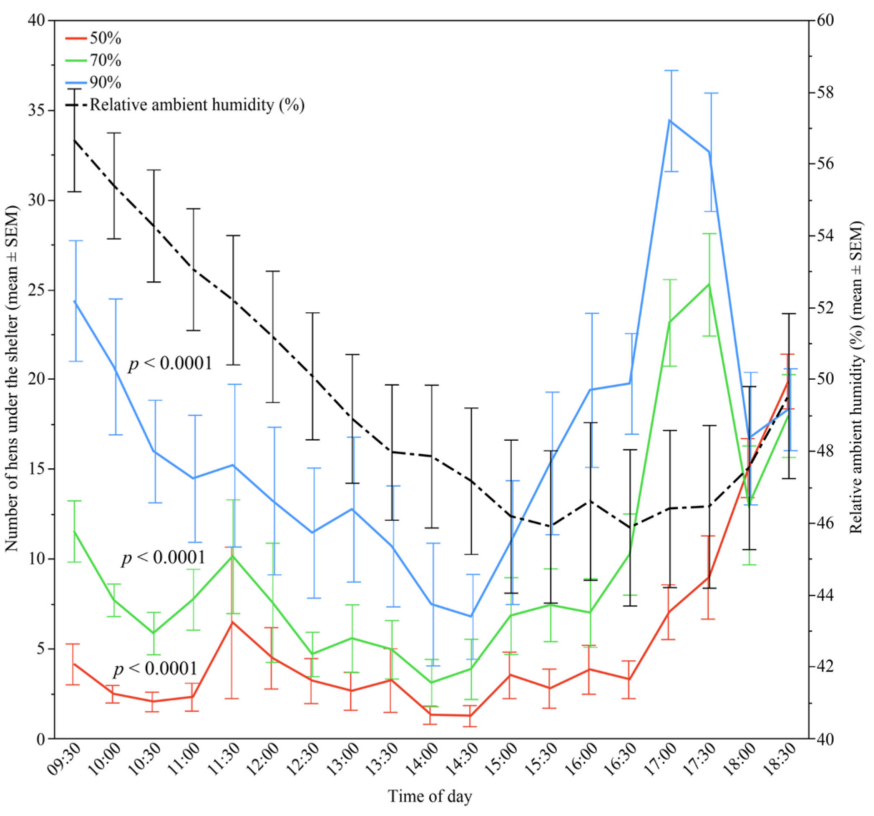

(a)

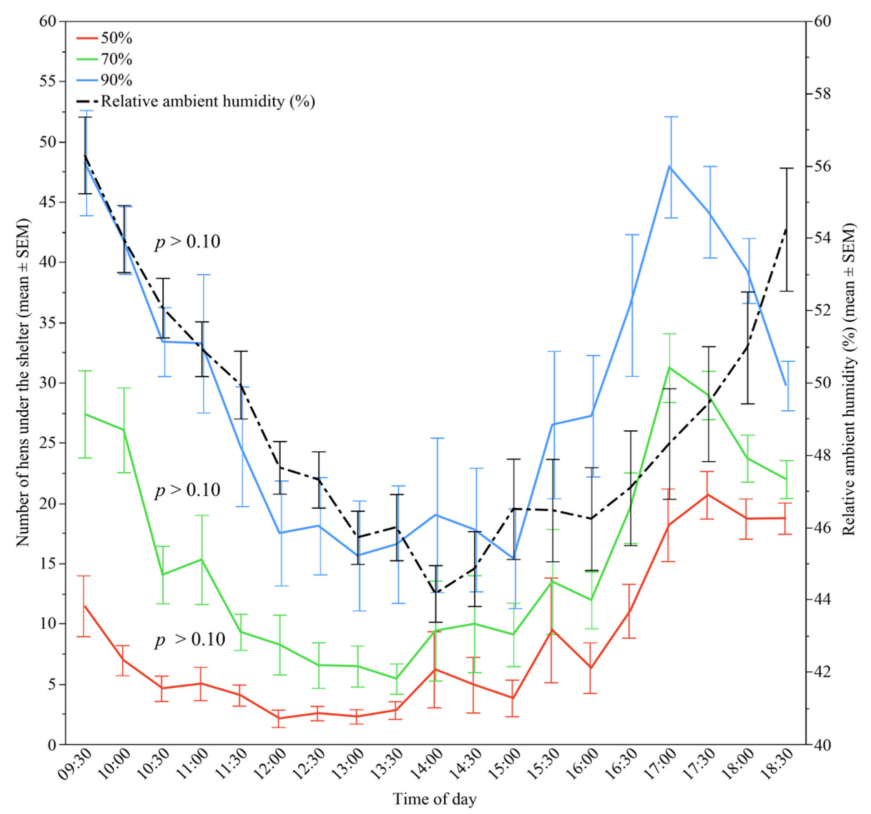

(b)

Figure 7. The mean $( \pm$ SEM) number of hens under the different UV-filtering shelters $(50 \%, 70 \%$, and $90 \%$ ) and the mean ( \pm SEM) relative ambient humidity throughout the day: (a) Flock-A; (b) Flock-B ( $p>0.10$ indicates the variable had no significant effect and was removed from final model). Note the different Y-axis scales between Flock-A and Flock-B. Raw values are presented with analyses conducted on transformed data.

$\mathrm{UV}_{\mathrm{AB}}$ radiation only had a significant effect for the $70 \% \mathrm{UV}$-filtering shelter preferences $(p<0.0001)$ in Flock-A where it was the most contributory effect $(45.57 \%$ variation) in that specific model (Figure 8). In contrast, $\mathrm{UV}_{\mathrm{AB}}$ radiation showed a significant relationship with the use of all shelter types in Flock-B (all $p \leq 0.01$ ) (Figure 8). The relative contribution of $\mathrm{UV}_{\mathrm{AB}}$ among the predictors in Flock-B for $50 \%, 70 \%$, and $90 \%$ UV-filtering shelter was $32.43 \%, 18.10 \%$, and $9.20 \%$, respectively, with the number of hens under the shelter decreasing with increasing $\mathrm{UV}_{\mathrm{AB}}$ radiation (Table 2 ).

In Flock-A, PAR had a significant negative correlation with the use by the hens of the $50 \%$ UV-filtering shelter $(p<0.0001)$ showing the greatest contributory effect $(64.86 \%$ variation, Table 2) in the model, and a positive trend for the $90 \%$ shelters $(p=0.07)$ but no association with use of the 70\% UV-filtering shelters (Figure 9). Whereas, in Flock-B, PAR was a significant contributing variable for use by the hens of the $90 \%$ UV-filtering shelters $(p<0.01)$, and it had a trend effect for the 70\% shelters $(p=0.10)$, but no significant contribution for the $50 \%$ UV-filtering shelters (Figure 9). While the relative weight of PAR in the models of $90 \%$ and $70 \%$ UV-filtering shelter preferences was $9.58 \%$ and $17.91 \%$, respectively, this had a positive relationship with the number of hens under the respective shelters, indicating increases in PAR also increased shelter use by the hens (Table 2). 


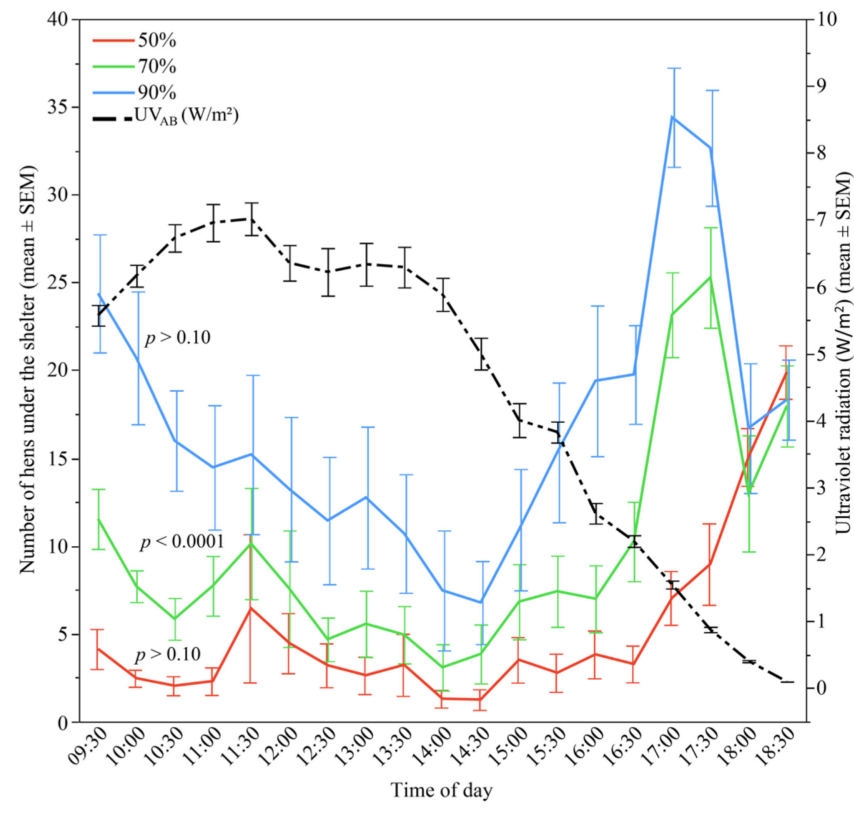

(a)

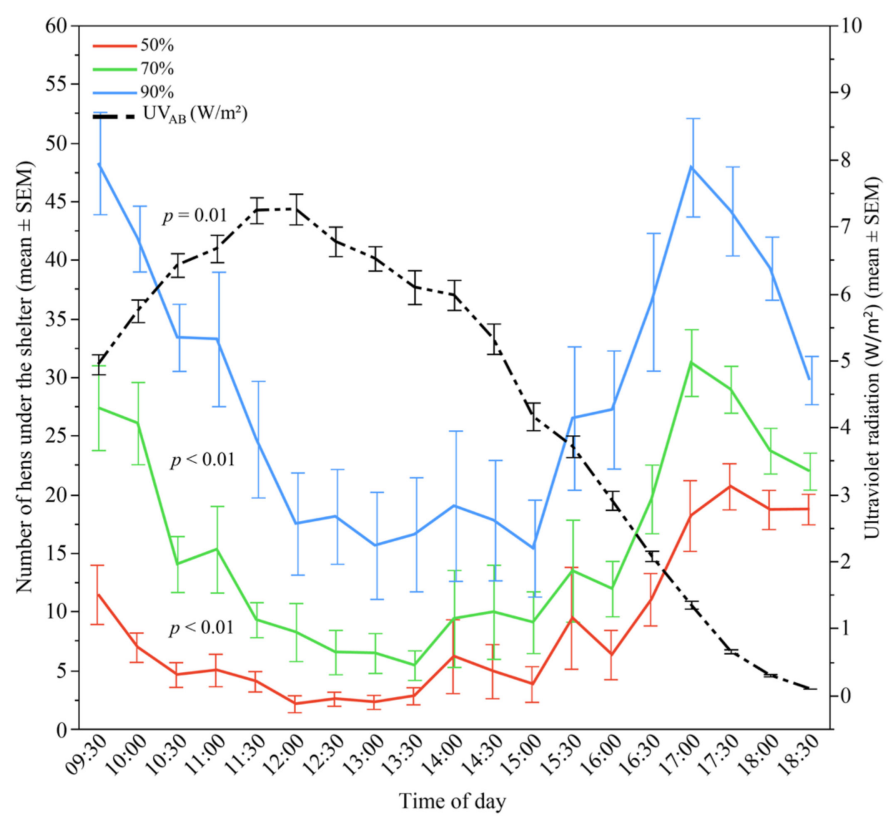

(b)

Figure 8. The mean $( \pm$ SEM) number of hens under the different $U V$-filtering shelters $(50 \%, 70 \%$, and $90 \%)$ and the mean $( \pm \mathrm{SEM})$ ultraviolet $\left(\mathrm{UV}_{\mathrm{AB}}\right)$ radiation throughout the day: (a) Flock-A; (b) Flock-B $(p>0.10$ indicates the variable had no significant effect and was removed from final model). Note the different Y-axis scales between Flock-A and Flock-B. Raw values are presented with analyses conducted on transformed data.

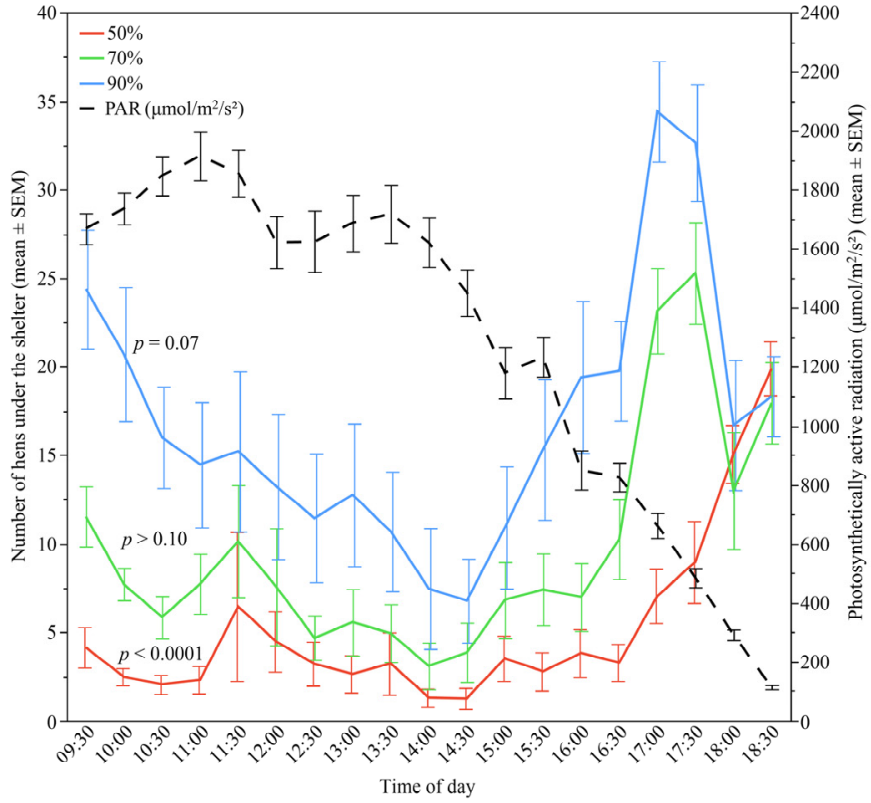

(a)

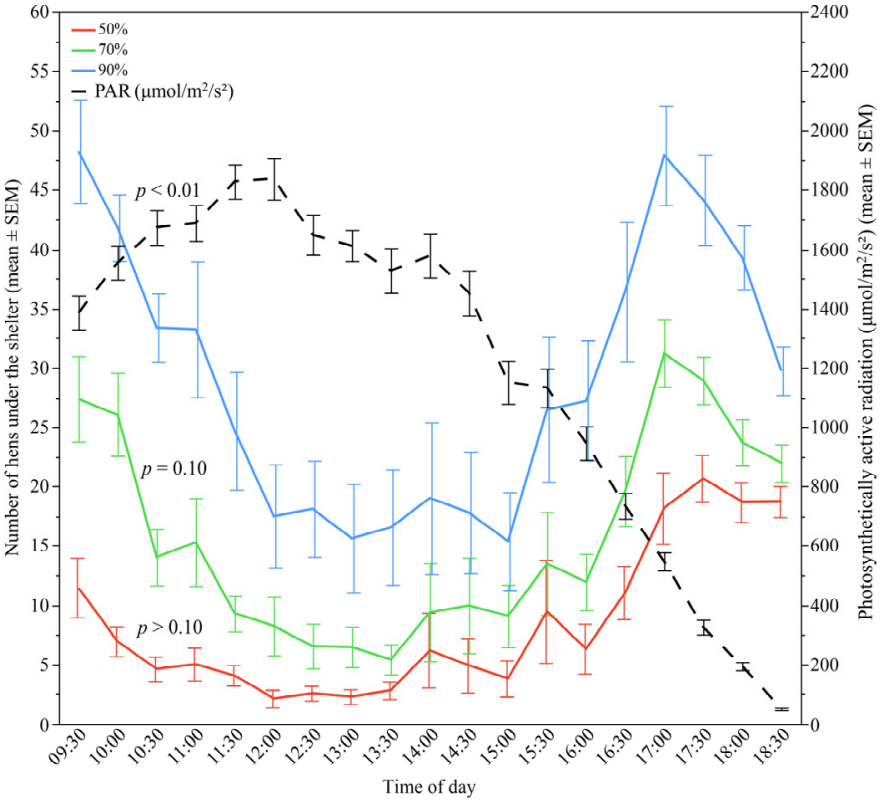

(b)

Figure 9. The mean $( \pm S E M)$ number of hens under the different UV-filtering shelters $(50 \%, 70 \%$, and $90 \%)$ and the mean $( \pm$ SEM) photosynthetically active radiation (PAR) throughout the day: (a) FlockA; (b) Flock-B ( $p>0.10$ indicates the variable had no significant effect and was removed from final model). Note the different Y-axis scales between Flock-A and Flock-B. Raw values are presented with analyses conducted on transformed data.

IR significantly affected shelter use of only the $90 \%$ UV-filtering shelters $(p<0.0001)$ in Flock-A. However, in Flock-B, IR significantly influenced shelter use of both the 70\% 
and 50\% UV-filtering shelters (both $p \leq 0.01$ ) and had a trend of an effect for the $90 \%$ UV-filtering shelters $(p=0.08)$ (Figure 10). However, a negative correlation between IR and use of shelters indicated that the number of hens under the shelters decreased when IR increased (Table 2).

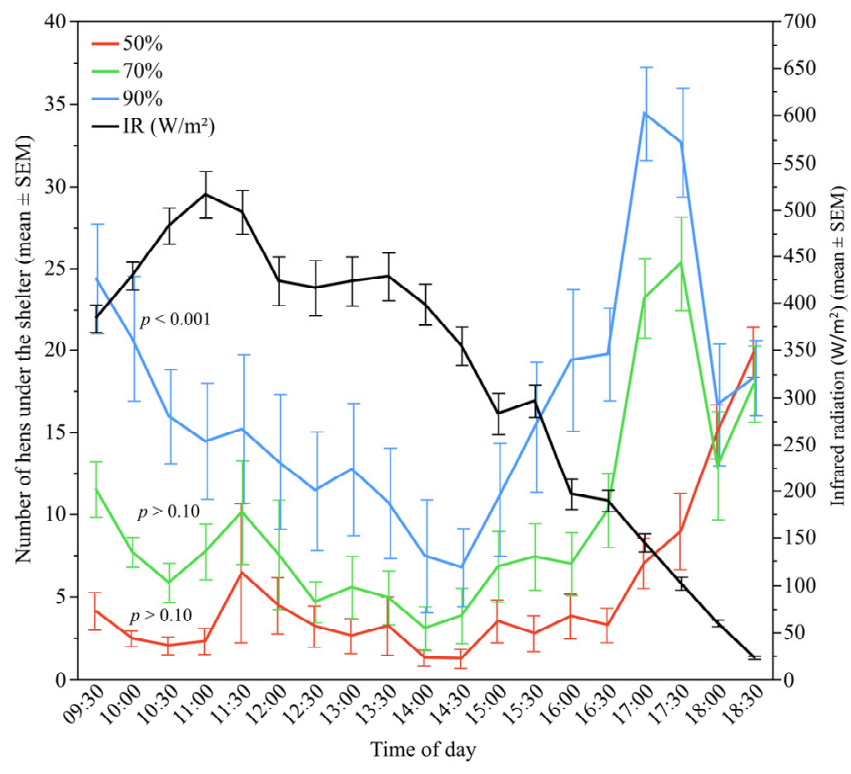

(a)

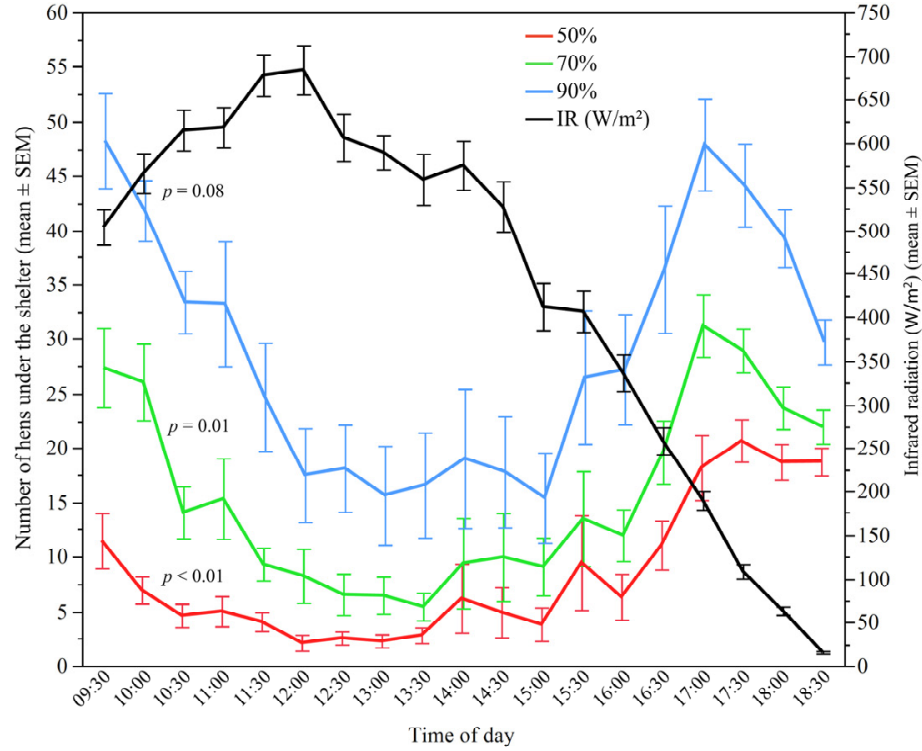

(b)

Figure 10. The mean $( \pm S E M)$ number of hens under the different UV-filtering shelters (50\%, 70\%, and $90 \%$ ) and the mean ( \pm SEM) infrared radiation (IR) throughout the day: (a) Flock-A; (b) Flock-B $(p>0.10$ indicates the variable had no significant effect and was removed from final model). Note the different $\mathrm{Y}$-axis scales between Flock-A and Flock-B. Raw values are presented with analyses conducted on transformed data.

\section{Discussion}

This study assessed the use by hens of different sunlight filtering shade cloth shelters on the range of a commercial farm in Australia. Different sunlight wavelengths were also measured directly on-farm to determine if shelter preferences were dependent on ambient conditions. The results showed that hens had clear preferences for shelters with the highest density, i.e., those that blocked the greatest amount of sunlight. However, relationships with temperature, humidity, and sunlight wavelengths were generally negative, with fewer hens under the shelters as the values of the weather parameters increased. This may have been a result of reduced ranging at times of peak sun intensity, which is consistent with the findings of previous studies.

Previous studies have shown that outdoor range enrichments will increase range use by hens and improve their distribution outside $[10,18,19,27]$. However, the effects of these enrichments can vary depending on the structural design, i.e., type (artificial/natural), location, height, orientation, and density $[16,17,29,30]$. Similar to other studies that have been conducted on commercial farms within Australia [17,29], the hens in our study showed clear preferences for the higher densities of the shade cloth with a linear relationship between use of the shelter and percentage of sunlight it filtered. These results confirm that hens can differentiate between shaded environments and will preferentially select the environment that provides the greatest amount of shaded protection. Anecdotal observations in the current study indicated that hens were sometimes crowded under the shade provided by trees on the range just beyond the artificial shelters, while shelters were comparatively empty. Formal counts were not made on this, as the camera position did not enable clear observations of hen numbers under the trees. This result aligns with the jungle fowl origins of domestic chickens, as well as previous observations that the greatest numbers of hens on commercial farms are attracted to natural shelter provided by trees [10], 
or will preferably gather under dense vegetation and established trees [30]. While hens may not always seek shelter on the range and may use the sunlight for sunbathing [41] and warmth [12], conditions of extreme heat and intense sunlight are likely more aversive than enticing. Temperatures were not taken under the trees on the range in this study, but they may have provided a cooler environment than under the shelters as a result of blocking more sunlight, as well as evaporative cooling from transpiration. While the temperatures were recorded as hotter under the shelters than the ambient temperature, the temperature loggers were sometimes in direct sunlight, and thus, we are limited in the conclusions we can draw from these results.

Environmental factors that explained the number of hens under the shelters were ambient temperature, $\mathrm{UV}_{\mathrm{AB}}$, and IR in both flocks, indicating that the overall use of shelters decreased with increasing intensity of these factors. The predominant influencing factor was ambient outdoor temperature. These results are in contrast to what was predicted, given that previous studies have shown that hens increase their use of shaded areas as temperatures increase, with few birds in nonshaded areas during the summer [18]. Richards et al. [12] reported that the percentage of hens ranging gradually decreased as temperatures increased above $17^{\circ} \mathrm{C}$, although the study was conducted in the UK, where much lower temperatures overall are experienced than those in the current study. Slow-growing broilers will increase their use of shelters as solar radiation increases [42,43], which is expected, given the damaging impact of UV light $[32,33]$ even though UV radiation was not found to be a predictor of range use in fast-growing broilers [34]. The hens in this study showed variation in shelter use throughout the day, regardless of shelter type, corresponding with typical patterns of range use reported in other studies [12,15,19], including observations in different flocks of the same farm as the current study [44]. Thus, the negative relationships between the environmental predictor variables were likely a reflection of fewer hens on the range during peak sun periods. General range use was not measured in this study, but the observed patterns of shelter use suggest that in regions of intense sunlight such as many regions of Australia, hens prefer to remain inside during the midday period, regardless of the presence or absence of artificial shelters on the range. Further studies could assess if more trees [10], different designs of artificial shelters [29] or additional range enrichments [18,26] could entice hens outside. If temperature is a key variable affecting the shelter preferences of hens, then shelter size may be another variable to consider, as well as the extent to which temperature varies under the edges or centre of the shelters. Alternatively, remaining inside the shed could prevent heat stress; in some regions of Australia, range use will be prevented on days of high heat to prevent bird mortality [44]. Further study assessing temperatures under different shelter types, established trees, shrubs, and inside sheds will confirm the different microclimates which exist in a free-range system and how they affect hen locational preferences.

The positive relationships seen between shelter use and the PAR wavelengths demonstrates that hens were using shelters to avoid bright light. This may have been comfortrelated, i.e., the same way humans will wear sunglasses or could be motivated to seek cover rather than being exposed to bright light. The $90 \%$ filtering shelter would have reduced the visibility of hens from above to a greater degree, and hens may have used it as protection from aerial predators $[26,28]$. This could also explain the higher use of shelters in the late afternoon, when sunlight wavelengths greatly decreased in intensity, but hens may still have been seeking protection from aerial predators. In contrast to this, hens also increased in numbers on top of the shelters in the late afternoon/evening, but this may have been related to a nighttime desire to roost [45]. While hens were kept inside the shed overnight, the setting sun may have stimulated motivation to seek elevation for those hens still ranging as sunset approached. These observations, in conjunction with environmental parameters only accounting for part of the variation in shelter use, indicate the interplay of many factors regarding a hen's decision to reside under a shelter versus in the open range area. 


\section{Conclusions}

This study found that higher densities of sunlight-filtering artificial cloth shelters are preferred by hens, and that temperature is a key variable affecting shelter use. All wavelengths of sunlight had some effect on shelter use, but the effect varied among the shelter densities and flocks in this study. The low use of all shelters during the midday period and negative relationships with temperature, humidity, $\mathrm{UV}_{\mathrm{AB}}$ and IR suggest that the shelters may not be sufficient for attracting more hens to the range in periods of intense sunlight and hot temperatures, during which hens are typically observed to range less. Range enrichments of both artificial and natural shelters may encourage more hens outside. In the absence of established trees on the range providing a larger canopy cover and reduced temperatures underneath, cooler conditions inside the shed may be preferable, but further research is needed to confirm this.

Supplementary Materials: The following supporting information can be downloaded at: https: / / www.mdpi.com/article/10.3390/ani12030344/s1, Figure S1: Snapshots of one of the $90 \%$ UVfiltering shelters in Flock-B showing use of the shelter and the immediate surrounding range area across one day.

Author Contributions: Conceptualisation, C.L. and D.L.M.C.; Data curation, M.S.R.; Formal analysis, M.S.R.; Funding acquisition, C.L. and D.L.M.C.; Investigation, M.S.R. and J.M.L.; Methodology, M.S.R., C.L., J.M.L. and D.L.M.C.; Resources, C.L., J.M.L. and D.L.M.C.; Supervision, C.L. and D.L.M.C.; Writing—original draft, M.S.R.; Writing—review \& editing, C.L. and D.L.M.C. All authors have read and agreed to the published version of the manuscript.

Funding: This research was funded by Australian Eggs, grant number: $31 \mathrm{HS} 902 \mathrm{CO}$ and the APC was funded by Australian Eggs. M.S. Rana was supported by an IPRA postgraduate scholarship through the University of New England and a Mcllrath Trust Scholarship through the Commonwealth Scientific and Industrial Research Organisation (CSIRO).

Institutional Review Board Statement: The study was conducted according to the guidelines of the Declaration of Helsinki, and approved by the Commonwealth Scientific and Industrial Research Organisation (CSIRO) Wildlife, Livestock and Laboratory Animal, Animal Ethics Committee (AEC approval number: 2020-27) although husbandry and management of the birds fell under the responsibility of the commercial farm.

Informed Consent Statement: Not applicable.

Data Availability Statement: Data that support this study will be made available upon any reasonable request to the corresponding author.

Acknowledgments: Thank you to Don Foster (CSIRO) for construction of the shelters, Tim Dyall (CSIRO) and Troy Kalinowski (CSIRO) for assistance with set-up and data collection, Andrew CohenBarnhouse for the spectroradiometer measurements, and Rowyn Hellyar (RDH Integration Services, Toowoomba, QLD) for camera system installation. The authors express great appreciation to the commercial farm staff for their willingness to host and support this research project.

Conflicts of Interest: The authors declare no conflict of interest. The funders had no role in the design of the study; in the collection, analyses, or interpretation of data; in the writing of the manuscript, or in the decision to publish the results.

\section{References}

1. Knierim, U. Animal welfare aspects of outdoor runs for laying hens: A review. NJAS Wagening. J. Life Sci. 2006, 54, 133-145. [CrossRef]

2. Miao, Z.; Glatz, P.; Ru, Y. Free-range poultry production-A review. Asian Australas. J. Anim. Sci. 2005, 18, 113-132. [CrossRef]

3. Shifaw, A.; Feyera, T.; Walkden-Brown, S.W.; Sharpe, B.; Elliott, T.; Ruhnke, I. Global and regional prevalence of helminth infection in chickens over time: A systematic review and meta-analysis. Poult. Sci. 2021, 100, 101082. [CrossRef] [PubMed]

4. Courtice, J.M.; Mahdi, L.K.; Groves, P.J.; Kotiw, M. Spotty Liver Disease: A review of an ongoing challenge in commercial free-range egg production. Vet. Microbiol. 2018, 227, 112-118. [CrossRef] [PubMed] 
5. Singh, M.; Ruhnke, I.; de Koning, C.; Drake, K.; Skerman, A.G.; Hinch, G.N.; Glatz, P.C. Demographics and practices of semiintensive free-range farming systems in Australia with an outdoor stocking density of $\leq 1500$ hens/hectare. PLoS ONE 2017, 12, e0187057. [CrossRef] [PubMed]

6. Moberly, R.; White, P.; Harris, S. Mortality due to fox predation in free-range poultry flocks in Britain. Vet. Rec. 2004, 155, 48-52. [CrossRef] [PubMed]

7. Bestman, M.; Bikker-Ouwejan, J. Predation in organic and free-range egg production. Animals 2020, 10, 177. [CrossRef]

8. Bari, M.S.; Downing, J.A.; Dyall, T.R.; Lee, C.; Campbell, D.L.M. Relationships between rearing enrichments, range use, and an environmental stressor for free-range laying hen welfare. Front. Vet. Sci. 2020, 7, 480. [CrossRef]

9. Rodriguez-Aurrekoetxea, A.; Estevez, I. Use of space and its impact on the welfare of laying hens in a commercial free-range system. Poult. Sci. 2016, 95, 2503-2513. [CrossRef]

10. De Koning, C.; Kitessa, S.M.; Barekatain, R.; Drake, K. Determination of range enrichment for improved hen welfare on commercial fixed-range free-range layer farms. Anim. Prod. Sci. 2019, 59, 1336-1348. [CrossRef]

11. Campbell, D.L.M.; Dyall, T.R.; Downing, J.A.; Cohen-Barnhouse, A.M.; Lee, C. Rearing enrichments affected ranging behavior in free-range laying hens. Front. Vet. Sci. 2020, 7, 446. [CrossRef] [PubMed]

12. Richards, G.; Wilkins, L.; Knowles, T.; Booth, F.; Toscano, M.; Nicol, C.; Brown, S. Continuous monitoring of pop hole usage by commercially housed free-range hens throughout the production cycle. Vet. Rec. 2011, 169, 338. [CrossRef] [PubMed]

13. Pettersson, I.C.; Freire, R.; Nicol, C.J. Factors affecting ranging behaviour in commercial free-range hens. World's Poult. Sci. J. 2016, 72, 137-150. [CrossRef]

14. Nicol, C.; Pötzsch, C.; Lewis, K.; Green, L. Matched concurrent case-control study of risk factors for feather pecking in hens on free-range commercial farms in the UK. Br. Poult. Sci. 2003, 44, 515-523. [CrossRef] [PubMed]

15. Gilani, A.M.; Knowles, T.G.; Nicol, C.J. Factors affecting ranging behaviour in young and adult laying hens. Br. Poult. Sci. 2014, 55, 127-135. [CrossRef]

16. Chielo, L.; Pike, T.; Cooper, J. Ranging behaviour of commercial free-range laying hens. Animals 2016, 6, 28. [CrossRef]

17. Rault, J.L.; Van De Wouw, A.; Hemsworth, P. Fly the coop! Vertical structures influence the distribution and behaviour of laying hens in an outdoor range. Aust. Vet. J. 2013, 91, 423-426. [CrossRef]

18. Nagle, T.A.; Glatz, P.C. Free range hens use the range more when the outdoor environment is enriched. Asian Australas. J. Anim. Sci. 2012, 25, 584-591. [CrossRef]

19. Hegelund, L.; Sørensen, J.T.; Kjaer, J.; Kristensen, I.S. Use of the range area in organic egg production systems: Effect of climatic factors, flock size, age and artificial cover. Br. Poult. Sci. 2005, 46, 1-8. [CrossRef]

20. Hartcher, K.M.; Hickey, K.A.; Hemsworth, P.H.; Cronin, G.M.; Wilkinson, S.J.; Singh, M. Relationships between range access as monitored by radio frequency identification technology, fearfulness, and plumage damage in free-range laying hens. Animal 2016, 10, 847-853. [CrossRef]

21. Campbell, D.L.M.; Hinch, G.N.; Downing, J.A.; Lee, C. Fear and coping styles of outdoor-preferring, moderate-outdoor and indoor-preferring free-range laying hens. Appl. Anim. Behav. Sci. 2016, 185, 73-77. [CrossRef]

22. Larsen, H.; Cronin, G.M.; Gebhardt-Henrich, S.G.; Smith, C.L.; Hemsworth, P.H.; Rault, J.L. Individual ranging behaviour patterns in commercial free-range layers as observed through RFID tracking. Animals 2017, 7, 21. [CrossRef] [PubMed]

23. Bestman, M.; Verwer, C.; Brenninkmeyer, C.; Willett, A.; Hinrichsen, L.; Smajlhodzic, F.; Heerkens, J.; Gunnarsson, S.; Ferrante, V. Feather-pecking and injurious pecking in organic laying hens in 107 flocks from eight European countries. Anim. Welf. 2017, 26, 355-363. [CrossRef]

24. Jung, L.; Brenninkmeyer, C.; Niebuhr, K.; Bestman, M.; Tuyttens, F.A.; Gunnarsson, S.; Sørensen, J.T.; Ferrari, P.; Knierim, U. Husbandry conditions and welfare outcomes in organic egg production in eight European countries. Animals 2020, $10,2102$. [CrossRef]

25. Barrett, J.; Rayner, A.; Gill, R.; Willings, T.; Bright, A. Smothering in UK free-range flocks. Part 1: Incidence, location, timing and management. Vet. Rec. 2014, 175, 19. [CrossRef]

26. Zeltner, E.; Hirt, H. Factors involved in the improvement of the use of hen runs. Appl. Anim. Behav. Sci. 2008, 114, 395-408. [CrossRef]

27. Zeltner, E.; Hirt, H. Effect of artificial structuring on the use of laying hen runs in a free-range system. Br. Poult. Sci. 2003, 44, 533-537. [CrossRef]

28. Hegelund, L.; Sørensen, J.; Hermansen, J. Welfare and productivity of laying hens in commercial organic egg production systems in Denmark. NJAS Wagening. J. Life Sci. 2006, 54, 147-155. [CrossRef]

29. Larsen, H.; Rault, J.-L. Preference for artificial range enrichment design features in free-range commercial laying hens. Br. Poult. Sci. 2021, 62, 311-319. [CrossRef]

30. Larsen, H.; Cronin, G.; Smith, C.L.; Hemsworth, P.; Rault, J.-L. Behaviour of free-range laying hens in distinct outdoor environments. Anim. Welf. 2017, 26, 255-264. [CrossRef]

31. Rana, M.S.; Campbell, D.L.M. Application of ultraviolet light for poultry production: A review of impacts on behavior, physiology, and production. Front. Anim. Sci. 2021, 2, 699262. [CrossRef]

32. Lewis, P.D.; Gous, R.M. Responses of poultry to ultraviolet radiation. World's Poult. Sci. J. 2009, 65, 499-510. [CrossRef]

33. Weihs, P.; Schmalwieser, A.W.; Schauberger, G. UV effects on living organisms. In Environmental Toxicology; Springer: New York, NY, USA, 2013; pp. 609-688. 
34. Taylor, P.S.; Hemsworth, P.H.; Groves, P.J.; Gebhardt-Henrich, S.G.; Rault, J.-L. Ranging behaviour of commercial free-range broiler chickens 1: Factors related to flock variability. Animals 2017, 7, 54. [CrossRef] [PubMed]

35. Primary Industries Standing Committee. Model Code of Practice for the Welfare of Animals_Domestic Poultry, 4th ed.; CSIRO Publishing: Collingwood, VIC, Australia, 2002.

36. Thimijan, R.W.; Heins, R.D. Photometric, radiometric, and quantum light units of measure: A review of procedures for interconversion. Hort. Sci. 1983, 18, 818-822.

37. R-Core-Team. R: A Language and Environment for Statistical Computing; R Foundation for Statistical Computing: Vienna, Austria, 2020. Available online: https:/ / www.r-project.org/index.html (accessed on 11 August 2020).

38. Schreiber-Gregory, D.N. Ridge Regression and multicollinearity: An in-depth review. Model Assist. Stat. Appl. $2018,13,359-365$. [CrossRef]

39. Ullah, M.I.; Aslam, M.; Altaf, S. Imridge: A comprehensive R package for Ridge regression. $R$ J. 2018, 10, 326-346. [CrossRef]

40. Grömping, U. Relative importance for linear regression in R: The package relaimpo. J. Stat. Softw. 2006, 17, 1-27. [CrossRef]

41. Duncan, I.J.; Widowski, T.M.; Malleau, A.E.; Lindberg, A.C.; Petherick, J.C. External factors and causation of dustbathing in domestic hens. Behav. Process. 1998, 43, 219-228. [CrossRef]

42. Stadig, L.M.; Rodenburg, T.B.; Ampe, B.; Reubens, B.; Tuyttens, F.A.M. Effect of free-range access, shelter type and weather conditions on free-range use and welfare of slow-growing broiler chickens. Appl. Anim. Behav. Sci. 2017, 192, 15-23. [CrossRef]

43. Stadig, L.; Rodenburg, T.; Ampe, B.; Reubens, B.; Tuyttens, F. Effects of shelter type, early environmental enrichment and weather conditions on free-range behaviour of slow-growing broiler chickens. Animal 2017, 11, 1046-1053. [CrossRef]

44. Rana, M.S.; Lee, C.; Lea, J.M.; Campbell, D.L.M. Relationship between sunlight and range use of commercial free-range hens in Australia. PLOS ONE 2021. submitted.

45. Olsson, I.A.S.; Keeling, L.J. Night-time roosting in laying hens and the effect of thwarting access to perches. Appl. Anim. Behav. Sci. 2000, 68, 243-256. [CrossRef] 